\title{
An investigation of perceptual biases in complex regional pain syndrome
}

\author{
Annick Lena De Paepe ${ }^{\text {Corresp., }}{ }^{2}$, Valéry Legrain ${ }^{2}$, Lien Van der Biest ${ }^{1}$, Nadine Hollevoet ${ }^{3}$, Alexander Van Tongel ${ }^{3}$, \\ Lieven De Wilde ${ }^{3}$, Herlinde Jacobs ${ }^{4}$, Geert Crombez ${ }^{1}$ \\ 1 Department of Experimental-Clinical and Health Psychology, Faculty of Psychology and Educational Sciences, Ghent University, Ghent, Belgium \\ 2 Institute of Neuroscience, Université Catholique de Louvain, Brussels, Belgium \\ 3 Department of Orthopaedic Surgery and Traumatology, Ghent University Hospital, Ghent, Belgium \\ 4 Unit of Physical Medicine, AZ Maria Middelares Hospital, Ghent, Belgium \\ Corresponding Author: Annick Lena De Paepe \\ Email address: Annick.DePaepe@UGent.be
}

Patients with complex regional pain syndrome (CRPS) report cognitive difficulties, affecting the ability to represent, perceive and use their affected limb. Moseley et al. (https://doi.org/10.1093/brain/awp224) observed that CRPS patients tend to bias the perception of tactile stimulation away from the pathological limb. Interestingly, this bias was reversed when CRPS patients were asked to cross their arms, implying that this bias is embedded in a complex representation of the body that takes into account the position of body-parts. Other studies have failed to replicate this finding (doi:10.1038/s41598-017-10077-8) or have even found a bias in the opposite direction (e.g. doi:10.1212/01.wnl.0000250242.99683.57). Moreover, perceptual biases in CRPS patients have not often been compared to these of other chronic pain patients. Chronic pain patients are often characterized by an excessive focus of attention for bodily sensations. We might therefore expect that non-CRPS pain patients would show a bias towards instead of away from their affected limb. The aim of this study was to replicate the study of Moseley et al. (https://doi.org/10.1093/brain/awp224) and to extend it by comparing perceptual biases in a CRPS group with two non-CRPS pain control groups (i.e. chronic unilateral wrist and shoulder pain patients). In a temporal order judgment (TOJ) task, participants reported which of two tactile stimuli, one applied to either hand at various intervals, was perceived as occurring first. TOJs were made, either with the arms in a normal (uncrossed) position, or with the arms crossed over the body midline. We found no consistent perceptual biases in either of the patient groups and in either of the conditions (crossed/uncrossed). Individual differences were large and might, at least partly, be explained by other variables, such as pain duration and temperature differences between the pathological and non-pathological hand. Additional studies need to take these variables into account by, for example, comparing biases in CRPS (and non-CRPS) patients Peer] reviewing PDF | (2019:09:41210:2:1:NEW 20'Feb 2020) 
in an acute versus a chronic pain state. 
1

\section{An investigation of perceptual biases in complex regional pain syndrome}

3

4 Annick Lena De Paepe ${ }^{1 *}$, Valéry Legrain ${ }^{2}$, Lien Van der Biest ${ }^{1}$, Nadine Hollevoet ${ }^{3}$, Alexander Van

5 Tongel $^{3}$, Lieven De Wilde ${ }^{3}$, Herlinde Jacobs ${ }^{4}$, Geert Crombez ${ }^{1}$.

6

$7{ }^{1}$ Department of Experimental - Clinical and Health Psychology, Faculty of Psychology and

8 Educational Sciences, Ghent University, Belgium.

9

${ }^{2}$ Institute of Neuroscience, Université Catholique de Louvain, Brussels, Belgium.

11

$12{ }^{3}$ Department of Orthopaedic Surgery and Traumatology, Ghent University Hospital, Ghent, 13 Belgium.

14

${ }^{4}$ Unit of Physical Medicine, AZ Maria Middelares Hospital , Ghent, Belgium.

16

17

* Corresponding author: Annick De Paepe, Henri Dunantlaan 2, B-9000 Gent, Belgium, Tel +32

20 Number of text pages: 30

21 Number of tables: 1

22 Number of figures: 5 


\section{Abstract}

Patients with complex regional pain syndrome (CRPS) report cognitive difficulties, affecting the ability to represent, perceive and use their affected limb. Moseley et al. (https://doi.org/10.1093/brain/awp224) observed that CRPS patients tend to bias the perception of tactile stimulation away from the pathological limb. Interestingly, this bias was reversed when CRPS patients were asked to cross their arms, implying that this bias is embedded in a complex representation of the body that takes into account the position of body parts. Other studies have failed to replicate this finding (doi:10.1038/s41598-017-10077-8) or have even found a bias in the opposite direction (e.g. doi:10.1212/01.wnl.0000250242.99683.57). Moreover, perceptual biases in CRPS patients have not often been compared to these of other chronic pain patients. Chronic pain patients are often characterized by an excessive focus of attention for bodily sensations. We might therefore expect that non-CRPS pain patients would show a bias towards instead of away from their affected limb. The aim of this study was to replicate the study of Moseley et al. ( https://doi.org/10.1093/brain/awp224 ) and to extend it by comparing perceptual biases in a CRPS group with two non-CRPS pain control groups (i.e. chronic unilateral wrist and shoulder pain patients). In a temporal order judgment (TOJ) task, participants reported which of two tactile stimuli, one applied to either hand at various intervals, was perceived as occurring first. TOJs were made, either with the arms in a normal (uncrossed) position, or with the arms crossed over the body midline. We found no consistent perceptual biases in either of the patient groups and in either of the conditions (crossed/uncrossed). Individual differences were large and might, at least partly, be explained by other variables, such as pain duration and temperature differences between the pathological and non-pathological hand. Additional studies need to take these variables into account by, for example, comparing biases in CRPS (and non-CRPS) patients in an acute versus a chronic pain state. 
60

61

62

63

64

65

66

67

68

69

\section{Introduction}

Complex regional pain syndrome (CRPS) is a chronic disorder associated with sensory, motor, autonomic and trophic symptoms such as pain, temperature change, skin color change, swelling, and limited movement in usually one limb. CRPS often follows a minor or mild trauma to a limb [1]. The pathophysiology of CRPS is complex and still poorly understood, encompassing both structural and functional changes of the central nervous system [2-9]. It has been shown that CRPS is associated with cognitive dysfunctions affecting the mental representation [10], the perception and the use of the affected part of the body [11]. Patients report that moving the affected limb is slow, requires effort and involves conscious control $[12,13]$. Studies have revealed that patients have difficulties with the perception of the shape and the position of the affected limb [14-19]. Moreover, it has been shown that CRPS is associated with a spatially-defined disruption of motor performance $[20,21]$. The limb may even feel disconnected from the body $[12,13]$. Some authors have argued that CRPS has similarities to hemispatial neglect $[11,13]$, a syndrome consecutive to a brain lesion and characterized by a deficit in perceiving and exploring stimuli at the side of space contralateral to the damaged cortical hemisphere $[22,23]$. However, the idea that the cognitive symptomatology in CRPS is akin to hemispatial neglect is contested [11,24-29].

Studies have shown that CRPS patients also tend to have more difficulties to perceive somatosensory stimuli applied to the affected part of the body [30,31]. For instance, Moseley et al. [32] used a temporal order judgment (TOJ) task, in which participants have to judge which of two tactile stimuli applied to either hand in rapid time succession was perceived as being delivered first. They showed that CRPS patients gave priority to the processing of the tactile stimulus applied to the healthy hand at the detriment of the processing of the stimulus applied to the affected hand. Intriguingly, this pattern was reversed when the hands were crossed over the body midline, that is, the line separating the body in two equal parts according to its sagittal plane. Priority was given to the processing of the stimulus applied on the affected hand to the 
86

87

88

89

90

91

92

93

94

95

96

97

98

99

100

101

102

103

104

105

106

107

108

109

110

111

112

113

114

detriment of the processing of the stimulus applied to the healthy hand. This pattern of result seems to indicate that CRPS patients have difficulties to perceive stimuli arising at the side of space corresponding to the pathological part of the body, rather than at their affected limb itself whatever its position. Furthermore, it indicates that the observed perceptual deficits cannot be accounted for by deficits at the peripheral coding and the spinal transmission of somatosensory inputs [33], but involve higher order cortical mechanisms [34]. Conversely, Filbrich et al. [35] used a similar TOJ tasks with either visual or vibrotactile stimuli and found that a bias towards the unaffected side of space was present only for the visual stimuli. Visuospatial biases in CRPS were also found in a study of Bultitude et al. [36] who have shown in addition that patients' judgements about lateralized visual stimuli can be impacted by the posture of the limb, that is, if the hands are crossed or uncrossed. These latter results suggest that lateral cognitive difficulties in CRPS are not only determined by which side of the body is affected, but also depend on the actual position of the pathological limb (see [37]). Moreover, Bultitude et al. [36] found that the strength of the attentional bias was predicted by scores on a self-report measure of body perception distortion, but not by pain intensity, time since diagnosis or affected body site.

Apart from the lack of clarity regarding the precise nature of the cognitive deficits in CRPS patients, the specificity of these deficits for CRPS still has to be demonstrated. CRPS patients' performance are rarely compared to those of patients suffering of other types of chronic pain conditions. For example, Frettlöh et al. [38] observed that patients with CRPS reported significantly more disownership feelings and underuse of their painful limb as compared to patients with chronic pain syndromes of other origins. However nothing is described about the exact nature of these non-CRPS conditions, and most importantly, whether the body is affected unilaterally or bilaterally. Similarly, despite the fact that Kolb et al. [26] did not notice any difference between patients suffering from CRPS and non-CRPS chronic pain conditions affecting upper limbs, it is worth noting that for an important number of patients $(8 / 20)$ of the non-CRPS chronic pain group both limbs were affected. Uematsu et al. [39] compared performances of CRPS patients to those of patients with post-herpetic neuropathic pain and observed shifts of visual subjective body midline judgments only for CRPS patients. Moseley et 
115 al. [40] found that imagined movements increased pain and swelling to the same extent in 116 patients with CRPS as compared to non-CRPS pain patients. However, CRPS patients were on

117 average slower to recognize their affected hand compared to their unaffected hand. This could

118 be in accordance with studies suggesting that non-CRPS chronic pain patients have a

119 heightened attention for bodily sensations $[41,42]$. We could therefore expect that these 120 patients, in contrast to CRPS patients, would show a perceptual bias towards their affected

121 limb, instead of away from their affected limb. One study of Moseley et al. [43] contradicts this 122 hypothesis. In this study unilateral back pain patients performed a TOJ task with tactile stimuli 123 delivered to either side of their lower back. Similar to the results found in CRPS patients, stimuli 124 presented on the unaffected side were prioritized in favor of those presented to the affected 125 side. However, no CRPS patients were included in this study, so no direct comparison between 126 CRPS and non-CRPS patients was made.

127 The aim of the study was to replicate the findings of Moseley et al. [32] on space-based 128 perceptual biases in patients with CRPS to clarify the exact nature of the cognitive deficits 129 observed in this patient group, and to extend these results by comparing a CRPS group with two 130 non-CRPS pain control groups to verify whether these space-based biases are specific to CRPS 131 patients. To this end, CRPS patients performed temporal order judgment tasks using pairs of 132 tactile stimuli applied to either hand, and their performances were compared to those of two 133 groups of patients with lateralized chronic pain but not from CRPS origin: a group patients with 134 unilateral wrist pain and a group of patients with unilateral shoulder pain. The TOJ task was 135 performed either with the arms in a normal uncrossed posture or with the arms crossed over 136 the body midline so that each arm laid in the opposite side of space. If lateralized cognitive 137 deficits are not specific for CRPS patients, we expected to observe biased TOJs also in the other 138 patient groups. In addition, given that somatosensory inputs can be spatially coded according to 139 different reference frames, different hypotheses can be proposed. If the direction of the biases 140 depends on an anatomical reference frame, they should affect the perception of the stimuli 141 applied on the pathological limb whatever its position in external space. On the contrary, if the 142 direction of the biases depends on an external space reference frame, they would not depend 
143 on the limb posture and participants' judgments should be biased towards the side of space in

144 which their affected limb normally resides [32].

\section{2. Methods}

\section{2.1. Participants}

147 Participants aged between 18 and 70 years were recruited from January 2014 until May

1482015 at Ghent university hospital and the Ghent Maria Middelares hospital. Three groups of

149 participants were recruited (see criteria below): (1) patients with Complex Regional Pain

150 Syndrome type I (CRPS) of one of the upper limbs, (2) patients with unilateral wrist pain and (3)

151 patients with unilateral shoulder pain. Participants from all groups were included when they

152 were native Dutch speaking and had experienced unilateral upper limb pain for longer than 3

153 months. They were excluded when they also reported pain at the opposite side of the body

154 with respect to their affected limb, nerve injury (e.g. CRPS type II), ongoing limb trauma or

155 recent (<3 weeks) surgery of the painful limb. At entry, all participants were tested with the

156 same battery of tests to either confirm (in case of CRPS patients), or rule out (in case of wrist

157 and shoulder pain patients) the diagnosis of CRPS according to the Budapest criteria (see

158 Appendix). All patients had normal or corrected to normal vision. We aimed at recruiting 20

159 patients in every group. The study was approved by the Ethics Committee of University Hospital

160 Ghent (registration number: 2013/706) in agreement with the Declaration of Helsinki. All

161 participants gave their written informed consent and received a compensation.

\section{2.2. Self-report measures}

163 Participants completed an ad hoc questionnaire assessing socio-demographic characteristics,

164 the Pain Grading Scale (PGS; [44]), and a Hand Dominance Questionnaire [45].

165 After each experimental block, a series of self-report items assessed i) the intensity of the 166 vibrotactile stimuli on each hand (Likert scale from 0 "not intense at all" to 10 "very intense");

167 ii) to what extent they were able to concentrate during the task (Likert scale from 0 "not at all"

168 to 10 "very well"); iii) to what extent they experienced the task as fatiguing (Likert scale from 0

169 "not at all" to 10 "very much"). At the end of the experiment, additional items assessed to what

170 extent participants iv) directed their attention to the vibrotactile stimuli; v) made an effort to 
171 complete the task; vi) experienced fear/tension during the task and vii) found the task

172 meaningful (all measured on a Likert scale from 0 "not at all" to 10 "very much"). Participants

173 also completed a set of self-report questionnaires (see full methods and recruitment flow

174 charts presented here: http://hdl.handle.net/1854/LU-7179946), but these results were not

175 used for the purpose of this study and are therefore not further discussed.

$176 \quad 2.3$ Stimuli and apparatus

177 Participants were seated in a dimly lit room with their hands, palms down, resting on a table

178 (see Figure 1). The distance between the edge of the table, near the trunk, and the index

179 fingers was $35 \mathrm{~cm}$ and the distance between both index fingers was $40 \mathrm{~cm} .35 \mathrm{~cm}$ in front of the 180 imaginary line connecting both index fingers, a red fixation LED was positioned in the middle of 181 this line. The participant's head was maintained static using a chin rest. To protect them from 182 any auditory distraction, all participants wore headphones through which continuous white 183 noise $(46 \mathrm{~dB})$ resounded. The experimenter was sitting opposite to and facing the participant.

Vibrotactile stimuli were delivered using two magnet linear actuators (C-2 TACTOR, Engineering Acoustics, Inc., Florida), attached to the sensory territory of the superficial radial nerve of each hand ( $10 \mathrm{~ms}$ duration, $200 \mathrm{~Hz}$ ). The actuators were driven by self-developed software and a controlling device that converted electrical signals (Watt) into oscillating movements of the actuators against the skin. The intensity of the vibrotactile stimuli were determined individually and matched between both hands by means of a double random staircase procedure, based on the staircase procedure of Levitt [46]. In the first part of the procedure, 16 stimuli presented on the left hand were judged relative to a reference stimulus with maximum intensity (power $=0.21$ Watt) on a 5-point Likert scale ranging from 1 ("almost no sensation") to 5 ("maximum intensity"). The intensity that corresponded to an average rating of 3 was selected as the stimulus intensity for the left hand and served as the reference stimulus for the second part of the staircase procedure. In the second part, another 16 stimuli were presented, now to the right hand, and were compared to the selected reference stimulus on the left hand on a 5-point Likert scale ( 1 = "more than less strong", 2 = "less strong", 3 = 
199

200

201

202

203

204

205

206

207

208

209

210

211

212

213

214

215

216

217

218

219

220

221

222

223

224

225

226

"equally strong", 4 = "stronger", 5 = "much stronger"). The intensity that resulted in an averaged rating of 3 was selected as the intensity for stimuli on the right hand.

\subsection{Procedure}

In the first phase of the study, participants completed the socio-demographic questionnaire, the Pain Grading Scale and the Hand Dominance Questionnaire ( 10 minutes). In the second phase, participants were seated and the diagnostic screening (interview + testing) for CRPS took place ( 20 minutes). In the third phase of the study ( 90 minutes) during which the TOJ task was performed, the experimenter attached the actuators to the hands and gave the participants instructions about the staircase procedure. Following this, the headphones were turned on and the staircase procedure was initiated. Responses were inserted manually on a keyboard by the experimenter. As soon as the staircase procedure was finished, headphones were temporarily removed.

During the TOJ task, participants were instructed to fixate their gaze on a red LED in front of them, to place their chin in the chin wrest and to keep their hands still on the table throughout the task. After receiving these instructions, headphones were turned back on. The TOJ task started with three practice blocks of increasing difficulty. In the first practice block (8 trials), participants were administered only one tactile stimulus in each trial ( 4 left and 4 right, in random order) and were asked to locate the stimulus ("left" versus "right") in order to practice response mapping. In the second practice block (12 trials), pairs of tactile stimuli were administered one to either hand and separated by the three largest stimulus onset asynchronies (SOA's) used during the experiment, i.e., $\pm 200, \pm 90$ or $\pm 55 \mathrm{~ms}$ (negative values indicating that the stimulus to the left hand was applied first, positive values that the stimulus to the right hand was applied first) [47]. Participants had to report verbally which of the stimuli they perceived as first delivered ("left first" versus "right first"). The third practice block (18 trials) was identical to the second but was made up of 18 trials and participants were asked to cross their hands over the body midline (which arm was on top was counterbalanced). When instructions were not completely understood, or if performance was suboptimal, practice blocks were repeated until performance was satisfactory. In addition, participants could only 
227 proceed from the third practice block to the first experimental block when a minimal 228 performance of $75 \%$ was achieved on trials with the highest SOA ( $\pm 200 \mathrm{~ms})$.

229 During the experiment proper, 4 blocks of 60 trials each were presented to the participants.

230 Each trial was made up of a pair of tactile stimuli one administered to the left and one on the 231 right hand, according to 5 possible SOAs ranging from 10 to $200 \mathrm{~ms}[48,49]$. The ten different 232 trial types $( \pm 200, \pm 90, \pm 55, \pm 30, \pm 10 \mathrm{~ms})$ were delivered six times each in the four blocks in 233 random order [47]. The position of the arms was either uncrossed or crossed. This position was 234 alternated between blocks and the order was counterbalanced across participants. Each trial 235 started with the illumination of the red fixation LED for 1s, followed by the first tactile stimuli of 236 the pair. Participants reported verbally on which hand they perceived the stimulus as first 237 delivered ("left hand" versus "right hand"), regardless of arm position. The experimenter 238 inserted these responses manually on a keyboard ( $\mathrm{a}=$ "left hand", $\mathrm{p}=$ "right hand").

239 Participants were asked to maintain a steady pace in responding and to be as accurately as 240 possible. After each experimental block, participants filled in the post-block items and 241 temperature was reassessed on the back of both hands.

\section{$242 \quad 2.5$ TOJ measures}

243 Based on the procedure of Spence, Shore and Klein [50], the proportion of trials on which participants reported the tactile stimulus on their painful limb first was calculated for each participant, for each SOA and for each posture (crossed vs. uncrossed arm position). A sigmoid function was then fitted to these proportions and a standardized cumulative normal distribution (probits) was used to convert the proportion of left hand/right hand first responses (left hand first when the left hand/wrist/shoulder was painful, right hand first when the right hand/wrist/shoulder was painful) into a z-score. The best-fitting straight line was computed for each participant and for both postures (crossed vs. uncrossed arm position) and the derived slope and intercept were used to calculate the point of subjective simultaneity (PSS) and the just noticeable difference (JND).

253

The PSS refers to the point at which a participant reports the two tactile stimuli (on the left 254 and right hand) as occurring first equally often. This point can be interpreted as the SOA value 
255 that corresponds to a 0.5 proportion of left hand/right hand first responses [50]. The PSS is

256 calculated by taking the opposite of the intercept and dividing this by the slope, both derived

257 from the best- fitting straight line. To simplify the interpretation, the sign of the PSS was

258 inversed for participants with pain on the right hand/wrist/shoulder. As such, the PSS indicates

259 how much time the stimulus on the unaffected limb had to presented before/after the stimulus

260 on the affected limb, in order to be perceived as simultaneous. A positive PSS thus reflects

261 biased TOJ at the advantage of stimuli applied on the affected limb and to the detriment of

262 those applied on the unaffected hand, regardless of arm position (crossed vs. uncrossed).

263 Similarly, negative PSS reflects biased TOJ at the advantage of stimuli of the unaffected hand

264 and to the detriment of stimuli of the affected hand.

265 The JND indicates the interval between both tactile stimuli (on the left and right hand)

266

267

268

269

270

271

272

273

274

275

276

277

278

279

280

281

282

needed to achieve a $75 \%$ correct performance and, as such, provides a standardized measure of the sensitivity of participants' temporal perception. It is calculated by dividing 0.675 by the slope of the best-fitting straight line [50] and corresponds to the value obtained by subtracting the SOA at which the best fitting straight line crosses the 0.75 point from the SOA at which the same line crosses the 0.25 point, and dividing it by 2 .

\subsection{Analyses}

PSS values and their corresponding JND values were excluded from the analyses, if one of following criteria was not met: (1) the absolute value of the PSS values had to be smaller than twice the largest SOA (i.e. $400 \mathrm{~ms}$ ); (2) the performance (\% correct answers) of the participants for the largest SOA (i.e. $200 \mathrm{~ms}$ ) had to be above $60 \%$ (i.e. well above chance level) in both postures (hands uncrossed versus crossed). Extremely large PSS values and low performance indicate that participants were not able to perform the task correctly even at large SOAs, where the task performance is expected to be nearly perfect. The difference in missing values between the uncrossed and the crossed position was compared using a chi-squared test for equality of proportions.

To investigate the equivalence of the average self-reported intensity for the left compared to the right hand, a repeated measures ANOVA was conducted with Hand (left versus right hand) 
283 as within-subjects' factor and Group (CRPS, shoulder pain, wrist pain) as between-subjects'

284 factor $^{1}$. The same analysis was used to compare the average intensity of the tactile stimulation,

285 as delivered by the apparatus, in Watt (W). The mean scores on the other self-report measures

286 (see section 2.2) were compared between the three patient groups with a one-way ANOVA.

287 To investigate whether there was a prioritization of stimuli on either the affected limb or the 288 unaffected limb, one-sample $t$-tests were performed. For each patient group we tested if the PSS values in the crossed and uncrossed posture differed significantly from $0 \mathrm{~ms}$. Next, in order to compare the PSS values across the different postures, results were analyzed using linear mixed effect models in R (ImerTest, [51]). Linear mixed effects models account for the correlations in within-subjects data by estimating subject-specific deviations (or random effects) from each population-level effect (or fixed effect) of interest (see [52] for an elaboration). We chose to analyze the data with linear mixed models because it is a more subject-specific model and it allows unbalanced data, unlike the classical general linear models which requires a completely balanced array of data [52]. All models included a random intercept conditional on subject. First, a model was fitted to investigate the influence of posture (uncrossed versus crossed hands) across patient groups (CRPS, shoulder or wrist pain) on the PSS values. Posture and group as well as their interaction effect were entered to the model as fixed factors and a random subject-based intercept was added to the model. This model was not simplified as it included only the main variables of interest. Second, a model was fitted for each patient group separately to explore the potential influence of individual difference variables: pain intensity at the moment of testing (0-10), pain duration (in months), affected side (left or right) and temperature difference (see Appendix) between the affected and unaffected limb measured immediately after each block. For five participants (two CRPS patients, three wrist pain patients) the measurements of the temperature of the limbs after each block was missing. For these participants the temperature difference was imputed by the median difference of their group. Two-way interactions between the four variables (pain intensity, pain duration, affected side and temperature difference) and posture were included in the model. We attempted to simplify the model to obtain the most parsimonious model that

\footnotetext{
${ }^{1}$ Note that data on the self-reported intensity of the tactile stimulation was missing for one shoulder pain patient.
} 
311 fitted the data. To achieve this, we systematically restricted the full model based on Akaike's

312 Information Criterion (AIC) [53]. A variable was only included in the model when it decreased

313 the AIC value with more than 2 units. Finally, a model was fitted to investigate the influence of

314 posture (uncrossed versus crossed hands) across patient groups (CRPS, shoulder or wrist pain)

315 on the JND values.

316 We did not a priori include or exclude participants based on their JND value. However, 317 sensitivity analyses were performed for both the PSS and JND to check whether excluding 318 participants with JND values larger than the largest SOA (i.e. < -200) changed the results 319 profoundly. Moreover, sensitivity analyses were performed excluding three patients who did 320 not fulfill the research criteria of CRPS (see section 2.1.1 and appendix).

321 The final models were fitted with REML estimation. The ANOVA table was inspected to test

322 hypotheses about main and interaction effects. Kenward-Roger approximations to the degrees 323 of freedom were used to adjust for small sample sizes [54]. The significance level was set at $p<$ 3240.05 . The regression coefficients $(\beta)$ and their associated confidence intervals were reported as 325 a measure of the effect size. Raw data and R scripts are available at

326 https://osf.io/x82wk/?view only=ecd3a2c52fce489c986ef08b241e8204.

\section{Results}

\subsection{Participants}

An overview of patient characteristics is presented in Table 1 and results from the diagnostic screening can be found in the Appendix (table A1). Although screening results were missing for 4 shoulder pain patients, it is very unlikely that these participants would have met the criteria for the diagnosis of CRPS as they never received the diagnosis of CRPS and also did not report pain on the upper extremities.

\subsubsection{Complex regional pain syndrome}

336

CRPS patients were initially diagnosed by their medical doctor. At the beginning of the research session the Budapest criteria were assessed by the researcher (see 
338

339

340

341

342

343

344

345

346

347

348

349

350

351

352

353

354

355

356

357

358

359

360

361

362

363

364

365

366

Appendix). The presence of nerve injury (CRPS type 2) was considered as an exclusion criterion. Sixteen CRPS patients (age: $M=51.31, S D=11.72$, range $=23-68$ years; 3 men, 2 ambidextrous at the moment of testing; average pain duration: $M=10.29$ months, SD $=9.93$ ) took part in this study (out of the 39 participants that were contacted, $41 \%$ ). The experiment was discontinued for one participant who was unable to perform the task adequately, and another had to be excluded due to contralateral upper limb pain at the time of the experiment. Three more participants did not meet the research criteria for the diagnosis of CRPS at the time of the experiment. Analyses were first performed including these participants. Next, a sensitivity analysis was performed, excluding these participants (11 participants; age: $M=48.27, S D=11.99$, range $=23-66$ years; 1 male; 2 ambidextrous; 3 left side painful; average pain duration: $M=7.45$ months, $S D=7.34$ ). See http://hdl.handle.net/1854/LU-7179946 for a more detailed overview of recruitment and inclusion.

\subsubsection{Unilateral wrist pain}

Patients with unilateral ulnar wrist pain $[55,56]$ were invited to take part in this study. Sixteen unilateral wrist pain patients (age: $M=39.69, S D=12.38$, range $=24-59$ years; 4 male; 5 left handed, 2 ambidextrous; 9 left side painful; average pain duration: $M=$ 24.38 months, $S D=28.25$ ) participated (out of the 46 participants that were contacted, 35\%). Participants could still be excluded after the study when they reported contralateral upper body pain at the time of the experiment or when the diagnostic screening resulted in a diagnosis of CRPS. However, none of the participants had to be excluded (see http://hdl.handle.net/1854/LU-7179946).

\subsubsection{Unilateral shoulder pain}

Patients with unilateral shoulder pain, due to frozen shoulder syndrome $[57,58]$ or rotator cuff syndrome [59-61], were invited to participate in this study. Twenty unilateral shoulder pain patients (age: $M=52.15, S D=7.58$, range $=40-64$ years; 9 male, 1 left handed, 5 ambidextrous; average pain duration: $M=21.39, S D=16.50$ ) took part (out of the 38 participants that were contacted, 53\%). Two participants who were unable to perform the task adequately, were excluded. Three additional participants 
367

368

369

370

371

372

373

374

375

376

377

378

379

380

381

382

383

384

385

386

387

388

389

390

391 were excluded due to contralateral upper body pain at the time of the experiment. In sum, 15 participants (age: $M=51.00, S D=8.94$, range $=35-64$ years; 7 men; 1 left handed, 5 ambidextrous; 6 left side painful; average pain duration: $M=23.80, S D=$ 17.02) were included for further analysis (see http://hdl.handle.net/1854/LU-7179946)

[enter Table 1 here]

\subsection{Self-report measures}

The results of the PGS are illustrated in Table 1. The mean self-reported intensity of the vibrotactile stimuli was low (left hand: $M=2.61, S D=2.64$; right hand: $M=3.00, S D=2.45$ ) and did not differ significantly between both hands $(F(1,42)=3.23, p=0.08)$ across all patient groups (interaction Hand $x$ Group: $F(2,42)=1.88, p=0.17$ ). Participants reported directing their attention to a large extent to the vibrotactile stimuli $(M=7.68, S D=2.52)$. They reported that they were able to concentrate well during the task $(M=7.21, S D=1.72)$ and that they found the task only mildly fatiguing $(M=2.80, S D=2.42)$. Participants made a large effort to complete the task $(M=7.95, S D=1.83)$, reported finding the task meaningful $(M=8.02, S D=1.42)$ and reported little fear/tension during the task $(M=1.91, S D=2.11)$. There were no significant differences between the three patient groups.

\subsection{Tactile intensities}

The mean intensity (in Watt) of the tactile stimuli, derived from the staircase procedure, was not significantly different between the left and the right hand (left: $M=0.094, S D=0.023$; right: $M=0.093, S D=0.045 ; F(1,39)=0.02, p=0.905)$ for none of the three patient groups (interaction hand $*$ group: $F(2,39)=1.51, p=0.233$ ). There were also no differences in intensity of the tactile stimuli between the affected and the unaffected hand (affected: $M=0.096, S D=$ 0.043; unaffected: $M=0.091, S D=0.027 ; F(1,39)=0.62, p=0.435)$ for none of the three patient groups (interaction hand $*$ group: $F(2,39)=0.37, p=0.691$ ). 
392

393

394

395

396

397

398

399

400

401

402

403

404

405

406

407

408

409

410

411

412

413

414

415

416

417

\subsection{PSS values}

\subsubsection{Missing values}

In the crossed hands posture, 10 PSS values (22\%) were excluded from the analyses: two values because they did not meet criterion 1 , four values did not meet criterion 2 , and finally three values were excluded because they did not meet both criteria. These values belonged to three CRPS patients (21\%), three shoulder pain patients (20\%) and four wrist pain patients (25\%). No values were excluded in the uncrossed hands posture. A chi-squared test indicated that the proportion missing values was significantly larger for the crossed than for the uncrossed posture $\left(\chi^{2}=11.25, p<0.001\right)$.

\subsubsection{Results for all groups}

PSS values for each patient group and each posture are displayed in Figure 2 . The onesample t-tests revealed that PSS values were not significantly different from 0 for each of the three groups both in the uncrossed (CRPS: $\mathrm{M}=-0.60,95 \% \mathrm{Cl}[-31.80$ to 30.60$], \mathrm{t}(13)=-0.04, p=$ 0.97; Shoulder: $\mathrm{M}=-10.33,95 \% \mathrm{Cl}[-31.42$ to 10.76$], \mathrm{t}(14)=-1.05, p=0.31$; Wrist: $\mathrm{M}=-1.45$, $95 \% \mathrm{Cl}[-21.06$ to 18.15$], \mathrm{t}(15)=-0.16, p=0.88)$ and the crossed (CRPS: $\mathrm{M}=-32.92,95 \% \mathrm{Cl}[-$ 78.89 to 13.06$], \mathrm{t}(10)=-1.60, p=0.14$; Shoulder: $\mathrm{M}=-7.05,95 \% \mathrm{Cl}[-49.79$ to 35.69$], \mathrm{t}(11)=-$ $0.36, p=0.72$; Wrist: $\mathrm{M}=-33.23,95 \% \mathrm{Cl}[-74.57$ to 8.11$], \mathrm{t}(11)=-1.77, p=0.10)$ posture.

\section{[enter Figure 2 here]}

The model investigating the main and interaction effect of group and posture revealed no significant effects (group: $\mathrm{F}(2,73.76)=0.14, p=0.87$; posture: $\mathrm{F}(1,38.65)=2.22, p=0.14$; group $x$ posture: $\mathrm{F}(2,38.83)=0.92, p=0.41)$, indicating that the PSS values did not differ significantly between the three groups and between the two postures.

\subsubsection{Individual difference variables}

CRPS patients. None of the variables (posture, pain intensity, pain duration, affected side and temperature difference) improved the fit of the model. None of the variables had a significant effect on the PSS values (all $\mathrm{F}<1.59$, all $p>0.24$ ). 
418 Shoulder pain patients. The final model included the main effect of posture, temperature 419 difference and pain duration and the interaction effect between posture and temperature 420 difference and posture and pain duration. The interaction effect between temperature 421 difference and posture $(\mathrm{F}(1,18.44)=5.44, p=0.03, \beta=-37.69, \mathrm{Cl}[-67.40$ to -7.98$])$ was 422 significant. Higher temperatures for the affected versus the unaffected limb are associated with 423 more positive PSS values in the uncrossed posture, but more negative PSS values in the crossed 424 posture (Figure 3). Interestingly, a paired samples t-test showed that for this patient group the 425 affected hand had a significantly higher temperature than the unaffected hand $(\Delta=0.06,95 \%$ $426 \mathrm{Cl}[0.008$ to 0.12$], \mathrm{t}(29)=2.35, p=0.03)^{2}$. None of the other main or interaction effects were 427 significant (all $\mathrm{F}<3.18$, all $p>0.09$ ).

428 Wrist pain patients. The final model included the main effect of temperature difference and 429 pain duration. In this model the main effect of temperature difference was significant $(\mathrm{F}(1)$ $43018.90)=8.51, \beta=12.25, \mathrm{Cl}$ [4.48 to 20.03]), indicating that higher temperatures for the affected 431 versus the unaffected limb are associated with more positive PSS values and thus a stronger 432 prioritization of the unaffected limb (Figure 3). The main effect of pain duration was not 433 significant $(F(1,11.53)=4.39, p=0.06, \beta=-0.74, \mathrm{Cl}[-1.44$ to -0.05$)$, but there was a trend 434 suggesting that longer symptom duration might be associated with more negative PSS values 435 (Figure 4).

\subsection{JND values}

JND values for each patient group and each posture are displayed in Figure 5. One CRPS patient had an extremely large JND value (-933.01) in the crossed posture. This participant was not a priori excluded from the analyses, but sensitivity analyses were performed to check whether excluding this participant changed the results (see section 3.8). The model

443 investigating the main and interaction effect of group and posture revealed a significant main

\footnotetext{
${ }^{2}$ Note that for the other two patient groups this difference was not significant (CRPS patients: $\Delta=0.52,95 \% \mathrm{Cl}$ [$0.62,1.66], \mathrm{t}(27)=0.93, p=0.36$; wrist pain patients: $\Delta=0.53,95 \% \mathrm{Cl}[-0.31,1.38], \mathrm{t}(31)=1.28, p=0.21)$.
} 
444 effect of posture $(F(1,35.72)=11.48, p=0.002, \beta=156.17, \mathrm{Cl}$ [66.13 to 246.21]), indicating that 445 participants had more difficulty with the task when their hands were crossed. The main effect 446 of group $(F(2,69)=1.64, p=0.20)$ and the interaction effect between group and posture $447(F(2,36.38)=0.74, p=0.48)$ were not significant.

448

450

451

452

453

454

455

456

457

458

459

460

461

462

463

464

465

466

467

468

469

470

471

[enter Figure 5 here]

\subsection{Sensitivity analyses}

\subsubsection{Exclusion based on JND values}

Five patients had a JND <-200 (1 CRPS patient, 3 shoulder pain patients, 1 wrist pain patient) and were excluded from the analyses. The JND of the other patients ranged from -198.07 to 43.48 .

For the PSS values, the model investigating the main and interaction effect of group and posture still revealed no significant effects (group: $\mathrm{F}(2,63.73)=0.28, p=0.75$; posture: $\mathrm{F}(1,33.30)=1.25, p=0.27$; group $x$ posture: $\mathrm{F}(2,33.71)=0.76, p=0.48)$. For all patient groups, the models controlling for individual difference variables were refitted. For the CRPS patients, the final model included the main effect of pain intensity, affected side, posture and temperature difference and the interaction effect between posture and temperature difference. There was a significant effect of affected side $(\mathrm{F}(1,7.78)=7.40, p=0.03, \beta=-78.07, \mathrm{Cl}[-133.44$ to -22.71$]$ ), indicating that patients with CRPS affecting the left side had significantly more positive PSS values than patients with CRPS affecting the right side of their body. The interaction effect between posture and temperature difference was marginally significant $(F(1,13.98)=4.40, p=0.05, \beta=16.52, \mathrm{Cl}[2.06$ to 30.98]). Higher temperatures for the affected versus the unaffected hand were associated with more positive PSS values. This association was stronger in the crossed versus the uncrossed posture. None of the other effects were significant (all $\mathrm{F}<4.60, p>0.06$ ). For the shoulder patients, the final model included the main effects of pain duration, posture and temperature difference and the interaction effects between temperature difference and posture and between pain duration and posture. The interaction effect between posture and temperature difference was significant $(F(1,12.74)=5.38, p=0.04$, $\beta=-34.64, \mathrm{Cl}[-61.39$ to -7.89$])$, indicating that lower temperatures for the affected versus the 
472 unaffected limb are associated with more positive PSS values in the crossed posture and more 473 negative PSS values in the uncrossed posture. Finally, the interaction effect between pain 474 duration and posture was also significant $(\mathrm{F}(1,7.68)=9.62, p=0.02, \beta=4.40, \mathrm{Cl}[1.68$ to 7.12$])$, 475 indicating that longer pain duration was associated with more positive PSS values in the crossed 476 posture, while there was no clear association in the uncrossed posture. None of the other 477 effects were significant (all $\mathrm{F}<3.31, p>0.20$ ). For the wrist pain patients, the final model 478 included the main effects of temperature difference and pain duration. The main effect of 479 temperature difference was significant $(\mathrm{F}(1,21.81)=8.62, p=0.008, \beta=14.05, \mathrm{Cl}[5.32$ to 480 22.79]), with lower temperature for the affected limb versus the unaffected limb associated 481 with more negative PSS values. The main effect of pain duration was not significant $(F(1,10.78)$ $482=4.13, p=0.07, \beta=-0.76, \mathrm{Cl}[-1.49$ to -0.03$]$ ), but there was a trend suggesting that longer pain 483 duration was associated with more negative PSS values.

484 For the JND values, the model investigating the main and interaction effect of group and 485 posture still revealed a significant main effect of posture $(F(1,32.75)=28.30, \beta=-65.66, \mathrm{Cl}[-$ 48689.73 to -41.60$]$ ), indicating that JND values were more negative in the crossed than in the 487 uncrossed posture. The main effect of group $(\mathrm{F}(2,62.78)=0.26, p=0.77)$ and the interaction 488 effect of group and posture $(F(2,33.14)=0.09, p=0.91)$ were not significant.

489 490 491 492

\subsubsection{Inclusion criteria CRPS}

Three CRPS patients did not fulfill the research criteria of CRPS (see section 2.1.1) during the diagnostic screening procedure. Keep in mind that these were initially diagnosed by a clinician. Analyses were performed again excluding these participants.

The final model included the fixed effect of posture, pain duration, pain intensity, and the interaction between posture and pain duration and posture and pain intensity. None of the main or interaction effects reached significance (all $\mathrm{F}<4.41, p>0.07$ ).

\section{Discussion}

The goal of this study was to replicate and extend the findings of Moseley et al. [29], by testing whether somatosensory impairments observed in previous studies [27,32,62] were specific to CRPS or whether they can also characterize other types of lateralized chronic pain. 
500 Temporal order judgment (TOJ) tasks were used to compare perceptual biases between tactile

501 stimuli applied to the affected or the unaffected limbs in patients with CRPS and patients with

502 lateralized pain in one limb from non-CRPS origins, i.e. patients with either wrist or shoulder

503 pain. Next, by asking patients to adopt different postures, i.e. the limbs uncrossed or crossed

504 over the body midline, we tested whether potential biases can be determined by either the side

505 of space corresponding to the affected hemibody or the actual position of the limbs during the

506 experiments. Finally, we assessed whether the difference between individuals in terms of

507 temperature difference between the affected versus the unaffected hand and the duration of

508 the pain, could influence temporal order judgments in the three patient groups.

509 In general, the results of this study did not support a bias to tactile stimuli in patients with

510 CRPS. First, the mean PSS values were not significantly different from zero, suggesting the

511 absence of a consistent bias at the advantage of one of the two stimulated body parts, neither

512 the affected nor the unaffected hand. This is in contrast with the results of previous studies

$513[27,32,62]$. Also, for the two other groups of unilateral chronic pain patients we found no

514 evidence for a perceptual bias. Second, there was no difference between judgements of the

515 CRPS patients and those of the non-CRPS patients. Inspection of the individual data show that

516 there was a substantial variability between patients, maybe hampering us to find any

517 systematic bias towards one side of space at the group level. Whereas some patients showed

518 more negative PSS values in the uncrossed versus the crossed posture, others showed the

519 opposite pattern. Present data are in line with a study of Filbrich et al. [35] who also did not

520 find a systematic spatial bias in a tactile TOJ task with CRPS patients. Moreover, the reverse

521 pattern of biases was also found. For instance, using the visual version of the subjective body

522 midline judgment task, some studies found systematic deviations of the judgments towards the

523 side of space corresponding to the affected part of the body $[39,63,64]$. Those results were

524 however not replicated by other teams $[26,65]$. The inconsistency in the literature with respect

525 to CRPS-related cognitive deficits might reflect substantial inter-individual differences in the

526 cognitive symptomatology of CRPS. It has been suggested that cognitive deficits are caused by a

527 maladaptive cortical reorganization consecutive to behavioral strategies used, even implicitly,

528 by the patients to avoid the provocation of pain [1]. Distinct strategies across the patients might 
529 therefore differentially influence cortical changes, and, as a consequence, impact patients' 530 behavior differently. Following this reasoning, we assessed for each patient group whether

531 individual difference variables (pain duration, temperature differences between the affected 532 and the unaffected hand, the side of CRPS symptoms and the intensity of the pain during 533 testing) affected the results of this study. We found some evidence that pain duration or 534 temperature differences between the affected and unaffected hand might play a role. It is 535 reasonable to think that the history of the pathology might influence the potential presence of 536 cognitive deficits. The longer duration of the pathology, the higher the probability to develop 537 cognitive deficits affecting the perception of the pathological limb. It could therefore be argued 538 that TOJ biases were masked in the present study by the data of the patients with more recent 539 CRPS.

540 It has to be noted that there are some differences in design or patient characteristics 541 between the present and previous studies [27,32,62] that may explain discrepancies in findings.

542 First, as mentioned above, the duration of the pathology might play a role in the presence of 543 cognitive deficits. Cognitive deficits might only be apparent after a longer duration of the 544 pathology. Previous studies [27,32,62] involved more chronic CRPS patients (average duration 545 of 30,20 and 32 months respectively) compared to the present study (average duration of 10 546 months). Second, in previous studies [32,62] participants were cold type CRPS (the affected arm 547 is cooler than the unaffected arm), whereas in the present study there was a mix between cold 548 and warm type CRPS (5 patients with cold type CRPS). It has been suggested that early CRPS is 549 associated with an increased temperature of the affected limb (warm type), while CRPS of 550 longer duration is associated with a decreased temperature of the affected limb (cold type) [1]. 551 The transition from hot to cold CRPS could be associated with a shift in spatially defined tactile 552 processing [32]. Third, the vibrotactile stimuli used in the present study were different from the 553 ones used in previous studies [27,32,62]. In previous studies, stimuli were presented by means 554 of bone conduction vibrators, which delivered vibrotactile stimuli to the finger pads. In the 555 present study the vibrotactile stimuli were delivered to the superficial radial nerve of each 556 hand. Nevertheless, it is important to point out that we have used these vibrotactile stimuli in 557 several other studies that succeeded to find biases in TOJs [41,66-67], using the same 
558 procedure to determine the intensity as used in the present study. Moreover, from Figure 2 it is 559 clear that for most participants a bias was present, but just not consistently to one side within a 560 patient group. Fourth, verbal reports were used to report which hand was stimulated first as 561 opposed to a foot switch. We decided to use verbal reports instead of a foot switch to make the 562 task easier for the participants. We worked with both verbal reports as well as a foot switch in 563 the past and were able to find biased order judgments with both response modalities [49].

564 Fifth, the experimenter sat opposite to and facing the participant instead of behind the 565 participant. Moreover, she was unblinded to the aim of the study and the patient group.

566 However, the experimenter was blinded to the particular trial that was presented and could 567 therefore not have influenced the results intentionally.

568 Conversely to the PSS values, we did observe significant results on the JND index. The JND, 569 standing for Just Noticeable Difference, is a measure of the slope of the psychometric functions 570 fitting participants' performances. It reflects the sensitivity of the task and the ability of the 571 participants to perform it (see [68]). In the present study, it reflects the minimal time interval 572 the participants need to perform the task with $75 \%$ correct responses (see $[68,69]$ for

573 alternative methods to measure the slope). The JND was significantly larger in the crossed hand 574 posture than in the uncrossed posture, meaning that the patients needed much more time to 575 discriminate the time order between the two tactile stimuli correctly when their arms were 576 crossed. Such an effect of posture on the participants' performance was present in the three 577 groups of patients and was already shown for CRPS patients in previous studies $[32,62]$ (but see 578 [70] for an exception). Decreased performance during TOJ tasks with somatosensory stimuli 579 when crossing the hands on which the stimuli are applied is a very recurrent and strong effect 580 throughout the literature (e.g. $[49,70-76])$. Such an effect is supposed to be due to a conflict 581 between a somatotopic representation of somatosensory stimuli, i.e. the ability to represent 582 them according to which body parts are stimulated, and a spatiotopic representation, i.e. the 583 ability to represent somatosensory sensations according to where the stimulated body parts 584 are located in external space. In other words, the crossing hand effect during somatosensory 585 TOJ illustrates the ability of the brain to remap somatosensory inputs from an initial 586 somatotopic or anatomical representation into a spatiotopic representation for which external 
587 space is used as reference frame (see [68]). The fact that CRPS patients do show an impaired 588 performance during tactile TOJ when their hands are crossed, just like healthy volunteers, 589 suggests that somatosensory remapping abilities are not affected in CRPS. Similarly, the data of 590 three CRPS patients were disregarded in the crossed hand posture, confirming that the task was

591 too difficult to perform for these patients in the crossed posture. In comparison, in a TOJ task 592 with somatosensory stimuli with healthy volunteers conducted in our lab, a larger range of 593 SOA's was used (largest SOA 600 ms). Nevertheless, two participants also had to be excluded 594 due to poor performance (less than 80\% correct) [77]. Future studies including a control group 595 with healthy volunteers could directly compare the JND for healthy volunteers versus CRPS 596 patients, to confirm that the remapping abilities for CRPS patients are similar to those of 597 healthy volunteers.

598 This study has some limitations. First, a small sample of patients was tested in each group 599 and an a-priori sample size calculation based on the study of Moseley et al. [32] was not 600 performed. Results of section 3.4 .3 (individual differences) should therefore be interpreted 601 with caution. Future studies should calculate the ideal sample size based on the effect sizes of 602 the present and previous studies $[27,32,62]$ and should presumably use a more important 603 sample size. Nevertheless, our sample of CRPS patients ( $N=14$ for the uncrossed posture and N $604=11$ for the crossed posture) was comparable to the sample used by Moseley et al. $[32,62](\mathrm{N}=$ 605 10) and Reid et al. [27] ( $N=13)$.

606 Second, for several patients the task was too difficult in the crossed posture as evidenced by 607 extremely large PSS values and consequently we were not able to use some of the data for the 608 crossed posture. This could have artificially reduced the effect of posture. Sensitivity analyses 609 showed that excluding these participants from the analyses did not drastically alter the results. 610 Future studies might choose to use data-adaptive methods (e.g. $[76,78])$ in which the tested

611 SOAs are adapted to each participant's own performance. This has the advantage that TOJ 612 parameters can be measured in a valid and reliable way without probing extensively all the 613 possible SOAs. 
614 Finally, we did not submit an a-priori locked protocol for this study. Current guidelines within 615 the pain field recommend to preregister the research plan before data collection [79]. It should

616 be noted that this study was conducted before the publication of these recommendations.

\section{Conclusion}

618 The results of this study did not support the hypotheses about the existence of systematic 619 and specific cognitive biases affecting the ability of CRPS patients to process their affected 620 hand. However, variability of the patients' data was large, suggesting that other factors, such as 621 duration of symptoms and temperature differences between the affected and unaffected limb, 622 might play a role in the development of cognitive deficits in CRPS. This could also be the case in 623 non-CRPS chronic pain patients, as skin temperature seemed to influence tactile TOJ in these 624 patients. Additional studies are needed that take these variables into account by, for example, 625 comparing biases in CRPS (and non-CRPS) patients in an acute versus a chronic pain state.

626

\section{Acknowledgments}

628 This study was part of a research project (G.0058.11N) granted by the Research Foundation 629 Flanders, Belgium (Fonds Wetenschappelijk Onderzoek [FWO]). Valéry Legrain is Research 630 Associate at the Fund for Scientific Research of the French speaking Community of Belgium 631 (F.R.S.-FNRS).

632

\section{Conflict of interest}

634 The authors declare that they have no conflict of interest.

635

636

637

638

639

\section{References}

[1] J. Marinus, G.L. Moseley, F. Birklein, R. Baron, C. Maihöfner, W.S. Kingery, J.J. van Hilten, Clinical features and pathophysiology of complex regional pain syndrome, Lancet Neurol. 10 (2011) 637-648. doi:10.1016/s1474-4422(11)70106-5. 
640 [2] K. Juottonen, M. Gockel, T. Silén, H. Hurri, R. Hari, N. Forss, Altered central

641 sensorimotor processing in patients with complex regional pain syndrome, Pain. 98

642 (2002) 315-323.

643

[3] P. Krause, S. Förderreuther, A. Straube, TMS motor cortical brain mapping in patients

644 with complex regional pain syndrome type I, Clin. Neurophysiol. 117 (2006) 169-176.

645 doi:10.1016/j.clinph.2005.09.012.

646

[4] C. Maihofner, R. Baron, R. DeCol, A. Binder, F. Birklein, G. Deuschl, H.O. Handwerker, 647 J. Schattschneider, The motor system shows adaptive changes in complex regional pain syndrome, Brain. 130 (2007) 2671-2687. doi:10.1093/brain/awm131.

649

[5] C. Maihöfner, C. Forster, F. Birklein, B. Neundörfer, H.O. Handwerker, Brain

650

651 processing during mechanical hyperalgesia in complex regional pain syndrome: $\mathrm{A}$ functional MRI study, Pain. 114 (2005) 93-103. doi:10.1016/j.pain.2004.12.001.

652

[6] C. Maihofner, H.O. Handwerker, B. Neundorfer, F. Birklein, Patterns of cortical

653

654 reorganization in complex regional pain syndrome, Neurology. 61 (2003) 1707-1715. doi:10.1212/01.WNL.0000098939.02752.8E.

655

[7] C. Maihöfner, H.O. Handwerker, B. Neundörfer, F. Birklein, Cortical reorganization 656

657 during recovery from complex regional pain syndrome, Neurology. 63 (2004) 693701.

[8] B. Pleger, B. Draganski, P. Schwenkreis, M. Lenz, V. Nicolas, C. Maier, M. Tegenthoff, 659 Complex regional pain syndrome type I affects brain structure in prefrontal and motor cortex, PLoS One. 9 (2014). doi:10.1371/journal.pone.0085372.

661

[9] B. Pleger, M. Tegenthoff, P. Ragert, A.F. Förster, H.R. Dinse, P. Schwenkreis, V. 662 Nicolas, C. Maier, Sensorimotor returning in complex regional pain syndrome 663 parallels pain reduction, Ann. Neurol. 57 (2005) 425-429. doi:10.1002/ana.20394.

664

[10] F. de Vignemont. Body schema and body image - pros and cons. Neuropsych. 48 665 (2009) 669-680. 
666

667

668

669

670

671

672

673

674

675

676

677

678

679

680

681

682

683

684

685

686

687

688

689

690

691

[11] V. Legrain, J.H. Bultitude, A.L. De Paepe, Y. Rossetti, Pain, body, and space: What do patients with complex regional pain syndrome really neglect?, Pain. 153 (2012) 948951. doi:10.1016/j.pain.2011.12.010.

[12] B.S. Galer, S. Butler, M.P. Jensen, Case reports and hypothesis: a neglect-like syndrome may be responsible for the motor disturbance in reflex sympathetic dystrophy (Complex Regional Pain Syndrome-1)., J. Pain Symptom Manage. 10 (1995) 385-391. doi:10.1016/0885-3924(95)00061-3.

[13] B.S. Galer, M. Jensen, Neglect-like symptoms in complex regional pain syndrome: Results of a self-administered survey, J. Pain Symptom Manage. 18 (1999) 213-217. doi:10.1016/S0885-3924(99)00076-7.

[14] G.L. Moseley, Why do people with complex regional pain syndrome take longer to recognize their affected hand?, Neurology. 62 (2004) 2182-2186.

doi:10.1212/01.WNL.0000130156.05828.43.

[15] G.L. Moseley, Distorted body image in complex regional pain syndrome, Neurology. 65 (2005) 773-778.

[16] J.S. Lewis, P. Kersten, K.M. McPherson, G.J. Taylor, N. Harris, C.S. McCabe, D.R. Blake, Wherever is my arm? Impaired upper limb position accuracy in complex regional pain syndrome, Pain. 149 (2010) 463-469. doi:10.1016/j.pain.2010.02.007.

[17] J. Schwoebel, R. Friedman, N. Duda, H.B. Coslett, Pain and the body schema: evidence for peripheral effects on mental representations of movement, Brain. 124 (2001) 2098-2104. doi:10.1093/brain/124.10.2098.

[18] J.S. Lewis, P. Kersten, C.S. McCabe, K.M. McPherson, D.R. Blake, Body perception disturbance: a contribution to pain in complex regional pain syndrome (CRPS)., Pain. 133 (2007) 111-119. doi:10.1016/j.pain.2007.03.013.

[19] A.J. Turton, M. Palmer, S. Grieve, T.P. Moss, J. Lewis, C.S. McCabe, Evaluation of a Prototype Tool for Communicating Body Perception Disturbances in Complex 
692

693

694

695

696

697

698

699

700

701

702

703

704

705

706

707

708

709

710

711

712

713

714

715

716

717

Regional Pain Syndrome, Front. Hum. Neurosci. 7 (2013) 1-8.

doi:10.3389/fnhum.2013.00517.

[20] J. Schwoebel, R. Friedman, N. Duda, H.B. Coslett, Pain and the body schema. Evidence for peripheral effects on mental representations of movement, Brain. 124 (2001) 2098-2104.

[21] E.J. Reid, F.A. Braithwaite, S.B. Wallwork, D. Harvie, K.J. Chalmers, C. Spence, A. Gallace, G.L. Moseley, Spatially-defined motor deficitis in people with unilateral complex regional pain syndrome, Cortex. 104 (2018) 154-162.

Doi:10.1016/j.cortex.2017.06.024

[22] M. Corbetta, Hemispatial Neglect : Clinic, Pathogenesis, and Treatment, Semin. Neurol. 34 (2014) 514-523. doi: 10.1055/s-0034-1396005.

[23] A.E. Hillis, Neurobiology of Unilateral Spatial Neglect, Neurosci. 12 (2006) 153-163. doi:10.1177/1073858405284257.

[24] T.D. Punt, L. Cooper, M. Hey, M.I. Johnson, Neglect-like symptoms in complex regional pain syndrome: Learned nonuse by another name?, Pain. 154 (2013) 200203. doi:10.1016/j.pain.2012.11.006.

[25] S. Förderreuther, U. Sailer, A. Straube, Impaired self-perception of the hand in complex regional pain syndrome (CRPS), Pain. 110 (2004) 756-761. doi:10.1016/j.pain.2004.05.019.

[26] L. Kolb, C. Lang, F. Seifert, C. Maihöfner, Cognitive correlates of "neglect-like syndrome" in patients with complex regional pain syndrome, Pain. 153 (2012) 10631073. doi:10.1016/j.pain.2012.02.014.

[27] E. Reid, S.B. Wallwork, D. Harvie, K.J. Chalmers, A. Gallace, C. Spence, G.L. Moseley, A New Kind of Spatial Inattention Associated with Chronic Limb Pain?, Ann. Neurol. 79 (2016) 701-704. doi:10.1002/ana.24616.

[28] M. Sumitani, M. Shibata, T. Iwakura, Y. Matsuda, G. Sakaue, T. Inoue, T. Mashimo, S. 
718

719

720

721

722

723

724

725

726

727

728

729

730

731

732

733

734

735

736

737

738

739

740

741

742

743

Miyauchi, Pathologic pain distorts visuospatial perception, Neurology. 68 (2007) 152154. doi:10.1212/01.wnl.0000250335.56958.f0.

[29] S. Jacobs, C. Brozzoli, A. Farnè, Neglect: A multisensory deficit?, Neuropsychol. 50 (2012) 1029-1044. doi:10.1016/j.neuropsychologia.2012.03.018.

[30] C.S. McCabe, R.C. Haigh, P.W. Halligan, D.R. Blake, Referred sensations in patients with complex regional pain syndrome type 1, Rheumatol. 42 (2003) 1067-1073. doi:10.1093/rheumatology/keg298.

[31] C. Maihöfner, B. Neundörfer, F. Birklein, H.O. Handwerker, Mislocalization of tactile stimulation in patients with complex regional pain syndrome, J. Neurol. 253 (2006) 772-779. doi:10.1007/s00415-006-0117-z.

[32] G.L. Moseley, A. Gallace, C. Spence, Space-based, but not arm-based, shift in tactile processing in complex regional pain syndrome and its relationship to cooling of the affected limb, Brain. 132 (2009) 3142-3151. doi:10.1093/brain/awp224.

[33] P. Schwenkreis, C. Maier, M. Tegenthoff, Functional Imaging of Central Nervous System Involvement in Complex Regional Pain Syndrome, Am. J. Neuroradiol. 30 (2009) 1279-1284. doi:10.3174/ajnr.A1630.

[34] W. Jänig, R. Baron, Complex regional pain syndrome is a disease of the central nervous system, Clin. Auton. Res. 12 (2002) 150-164. doi:10.1007/s10286-002-00221.

[35] L. Filbrich, A. Alamia, C. Verfaille, A. Berquin, O. Barbier, X. Libouton, V. Fraselle, D. Mouraux, V. Legrain, Biased visuospatial perception in complex regional pain syndrome, Sci. Rep. 7 (2017). doi:10.1038/s41598-017-10077-8.

[36] J.H. Bultitude, I. Walker, C. Spence, Space-based bias of covert visual attention in complex regional pain syndrome, Brain. 140 (2017) 2306-2321. doi:10.1093/brain/awx152.

[37] V. Legrain, Lost in space: do somatic symptoms affect the perception of extra-somatic 
744

745

746

747

748

749

750

751

752

753

754

755

756

757

758

759

760

761

762

763

764

765

766

767

768

769

stimuli?, Brain. 140 (2017) 2254-2264.

[38] J. Frettlöh, M. Hüppe, C. Maier, Severity and specificity of neglect-like symptoms in patients with complex regional pain syndrome (CRPS) compared to chronic limb pain of other origins, Pain. 124 (2006) 184-189. doi:10.1016/j.pain.2006.04.010.

[39] H. Uematsu, M. Sumitani, A. Yozu, Y. Otake, M. Shibata, T. Mashimo, S. Miyauchi, Complex regional pain syndrome (CRPS) impairs visuospatial perception, whereas post-herpetic neuralgia does not: Possible implications for supraspinal mechanism of CRPS, Ann. Acad. Med. Singapore. 38 (2009) 931-936.

[40] G.L. Moseley, N. Zalucki, F. Birklein, J. Marinus, J.J. van Hilten, H. Luomajoki, Thinking about movement hurts: The effect of motor imagery on pain and swelling in people with chronic pain, Arthritis Rheum. 59 (2008) 623-631. doi:10.1002/art.23580

[41] C. Van den Bulcke, S. Van Damme, W. Durnez, G. Crombez, The anticipation of pain at a specific location of the body prioritizes tactile stimuli at that location, Pain. 154 (2013) 1464-1468.

[42] M.L. Peeters, J.W.S. Vlaeyen, C. van Drunen, Do fibromyalgia patients display hypervigilance for innocuous somatosensory stimuli? Application of a body scanning reaction time paradigm, Pain. 86 (2000) 283-292.

[43] G.L. Moseley, L. Gallagher, A. Gallace. Neglect-like tactile dysfunction in chronic back pain, Neurology 79 (2012) 327-332.

[44] M. Von Korff, J. Ormel, F.J. Keefe, S.F. Dworkin, Grading the severity of chronic pain, Pain. 50 (1992) 133-149.

[45] J.W. Van Strien, Classificatie van links- en rechtshandige proefpersonen (Classification of left- and right-handed subjects), Ned. Tijdschr. Psychol. 47 (1992) 88-92.

[46] H. Levitt, Transformed Up-Down Methods in Psychoacoustics, J. Acoust. Soc. Am. 49 (1971) 467-477.

[47] A. Gallace, C. Spence, Visual capture of apparent limb position influences tactile 
770

771

772

773

774

775

776

777

778

779

780

781

782

783

784

785

786

787

788

789

790

791

792

793

794

temporal order judgments, Neurosci Lett. 379 (2005) 63-68.

doi:10.1016/j.neulet.2004.12.052.

[48] A.L. De Paepe, G. Crombez, C. Spence, V. Legrain, Mapping nociceptive stimuli in a peripersonal frame of reference: Evidence from a temporal order judgment task, Neuropsychologia. 56 (2014) 219-228. doi:10.1016/j.neuropsychologia.2014.01.016.

[49] A.L. De Paepe, G. Crombez, V. Legrain, From a Somatotopic to a Spatiotopic Frame of Reference for the Localization of Nociceptive Stimuli, PLoS One. 10 (2015) e0137120. doi:10.1371/journal.pone.0137120.

[50] C. Spence, D.I. Shore, R.M. Klein, Multisensory prior entry., J. Exp. Psychol. Gen. 130 (2001) 799-832. doi:10.1037/0096-3445.130.4.799.

[51] A. Kuznetsova, P.B. Brockhoff, R.H.B. Christensen, ImerTest Package: Tests in Linear Mixed Effects Models., J. Stat. Softw. 82 (2017) 1-26. doi:10.18637/jss.v082.i13.

[52] B.T. West, K.B. Welch, A.T. Galecki, Linear mixed models: A practical guide using statistical software, Chapman and Hall/CRC, London, 2007.

[53] Y. Sakamoto, M. Ishiguro, G. Kitagawa, Akaike information criterion statistics, KTK Scientific Publishers, Tokyo, 1986.

[54] M.G. Kenward, J.H. Roger, Small Sample Inference for Fixed Effects from Restricted Maximum Likelihood, Biometrics. 53 (1997) 983-997.

[55] R. Nakamura, Diagnosis of ulnar wrist pain, Nagoya J. Med. Sci. 64 (2001) 81-91. papers3://publication/uuid/874DDA5C-6DF4-47F0-827B-94075E831747.

[56] A.Y. Shin, M.A. Deitch, K. Sachar, M.I. Boyer, Ulnar-Sided Wrist Pain: Diagnosis and Treatment, J. Bone Joint Surg. 54 (2004) 1560-1574.

[57] J. Lewis, Frozen shoulder contracture syndrome - Aetiology, diagnosis and management, Man. Ther. 20 (2015) 2-9. doi:10.1016/j.math.2014.07.006.

[58] C.M. Robinson, K.T.M. Seah, Y.H. Chee, P. Hindle, I.R. Murray, Frozen shoulder, J. 
Bone Joint Surg Br 94 (2012) 1-9. doi:10.1302/0301-620X.94B1.27093.

796

[59] J. Beaudreuil, R. Nizard, T. Thomas, M. Peyre, J.P. Liotard, P. Boileau, T. Marc, C.

797 Dromard, E. Steyer, T. Bardin, P. Orcel, G. Walch, Contribution of clinical tests to the

798

799 diagnosis of rotator cuff disease: A systematic literature review, Jt. Bone Spine. 76 (2009) 15-19. doi:10.1016/j.jbspin.2008.04.015.

[60] P.C. Hughes, N.F. Taylor, R.A. Green, Most clinical tests cannot accurately diagnose 801 rotator cuff pathology: A systematic review, Aust. J. Physiother. 54 (2008) 159-170. doi:10.1016/S0004-9514(08)70022-9.

803

[61] U.G. Longo, A. Berton, P.M. Ahrens, N. Maffulli, V. Denaro, Clinical tests for the 804 diagnosis of rotator cuff disease, Sports Med. Arthrosc. 19 (2011) 266-278.

805 doi:10.1097/JSA.0b013e3182250c8b.

806

[62] G.L. Moseley, A. Gallace, G.D. Iannetti, Spatially defined modulation of skin 807 temperature and hand ownership of both hands in patients with unilateral complex 808 regional pain syndrome, Brain. 135 (2012) 3676-3686. doi:10.1093/brain/aws297.

809

[63] M. Sumitani, Y. Rossetti, M. Shibata, Y. Matsuda, G. Sakaue, T. Inoue, T. Mashimo, S. 810 Miyauchi, Prism adaptation to optical deviation alleviates pathologic pain, Neurology. 68 (2007) 128-133. doi:10.1212/01.wnl.0000250242.99683.57.

[65] A. Reinersmann, J. Landwehrt, E.K. Krumova, S. Ocklenburg, O. Güntürkün, C. Maier, Impaired spatial body representation in complex regional pain syndrome type 1 (CRPS I), Pain. 153 (2012) 2174-2181. doi:10.1016/j.pain.2012.05.025. bodily threat limited to the exact location where pain is expected? Acta Psychol. 153 (2014) 113-119. 
821 [67] C. Vanden Bulcke, G. Crombez, W. Durnez, S. Van Damme, Is attentional prioritization

822 on a location where pain is epected modality-specific or multisensory? Conscious

823 cogn. 36 (2015) 264-255.

824

[68] T. Heed, E. Azañón, Using time to investigate space : a review of tactile temporal

825 order judgments as a window onto spatial processing in touch, Cell. 5 (2014) 1-16.

826 doi:10.3389/fpsyg.2014.00076.

827

[69] L. Filbrich, A. Alamia, S. Burns, V. Legrain, Orienting attention in visual space by 828

829

830 nociceptive stimuli: investigation with a temporal order judgment task based on the adaptive PSI method, Exp. Brain Res. 235 (2017) 2069-2079. doi:10.1007/s00221017-4951-2.

831

[70] S. Yamamoto, S. Kitazawa, Reversal of subjective temporal order due to arm crossing, 832 Nat. Neurosci. 4 (2001) 759-765.

833

[71] D.I. Shore, E. Spry, C. Spence, Confusing the mind by crossing the hands, Cogn. Brain 834 Res. 14 (2002) 153-163. doi:10.1016/S0926-6410(02)00070-8.

835

[72] C.F. Sambo, D.M. Torta, A. Gallace, M. Liang, G.L. Moseley, G.D. lannetti, The 836

837

838 temporal order judgement of tactile and nociceptive stimuli is impaired by crossing the hands over the body midline, Pain. 154 (2013) 242-247. doi:10.1016/j.pain.2012.10.010.

[73] E. Azañón, S. Soto-Faraco, Changing reference frames during the encoding of tactile events., Curr. Biol. 18 (2008) 1044-9. doi:10.1016/j.cub.2008.06.045.

841

[74] M. Wada, S. Yamamoto, S. Kitazawa, Effects of handedness on tactile temporal order 842 judgment, Neuropsychol. 42 (2004) 1887-1895. doi:10.1016/j.neuropsychologia.2004.05.009.

[75] V. Crollen, G. Albouy, F. Lepore, O. Collignon, How visual experience impacts the 845 internal and external spatial mapping of sensorimotor functions, Sci Rep 7 (2017) 1022. doi:10.1038/s41598-017-01158-9. 
847 [76] C. Vanderclausen, M. Bourgois, A. De Volder, V. Legrain, Testing the exteroceptive 848 function of nociception: the role of visual experience in shaping the spatial 849 representations of nociceptive inputs, Cortex (in press) 1-28.

850 [77] C. Vanden Bulcke \& S. Van Damme (unpublished manuscript). Exploring the limits of 851 attentional prioritization of a threatened bodily location: the confusing effect of 852 crossing the arms. In: C. Vanden Bulcke (2015). Hypervigilance and pain: the role of 853 854

855

856 bodily threat (Doctoral dissertation, Ghent University, Ghent, Belgium). Retrieved from: https://biblio.ugent.be/publication/6930681

[78] L.L. Kontsevich, C.W. Tyler, Bayesian adaptive estimation of psychometric slope and threshold, Vision Res. 39 (1999) 2729-2737. doi:10.1016/S0042-6989(98)00285-5.

857 [79] H. Lee, S.E. Lamb, M.K. Bagg, E. Toomey, A.G. Cashin, G.L. Moseley, Reproducible and 858 replicable pain research: a cricital review, Pain. 159 (2018) 1683-1689.

859 doi:10.1097/j.pain.0000000000001254

860

861 
Figure 1

Experimental set-up of the TOJ task

(A) uncrossed arms condition. (B) crossed arms condition.

A

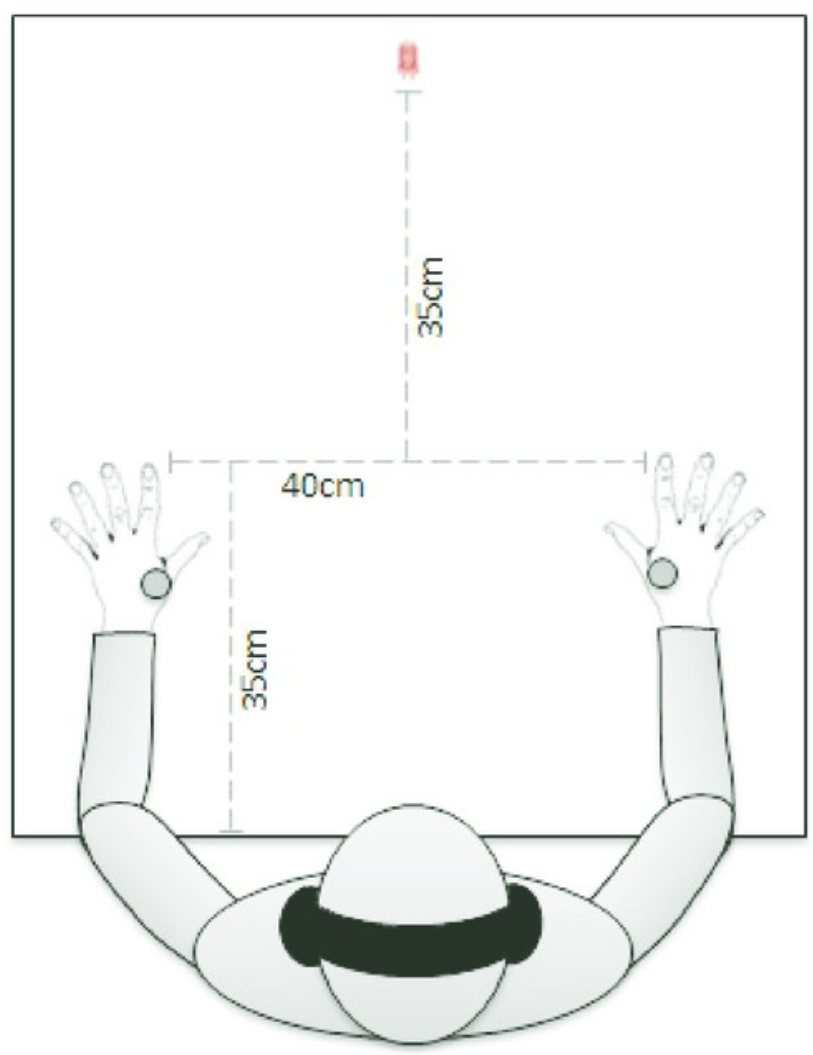

$B$

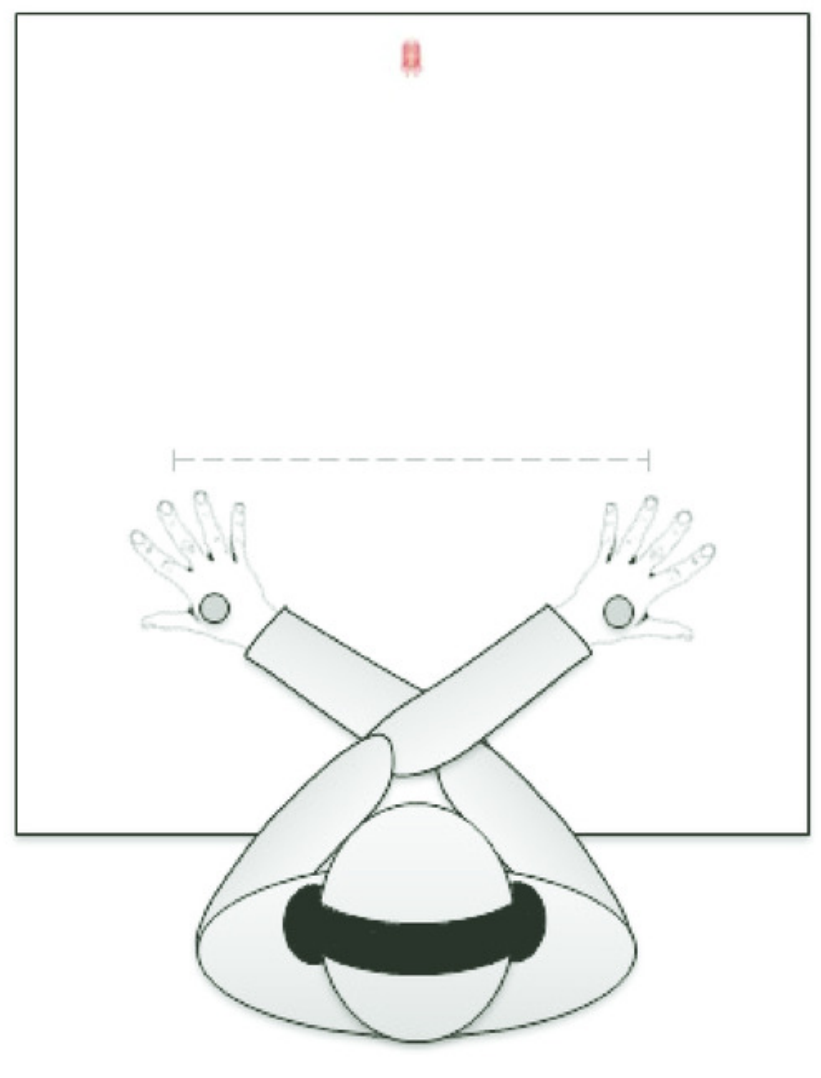


Figure 2

Individual and mean PSS values

Individual (black) and mean (grey) PSS values per group and per posture.

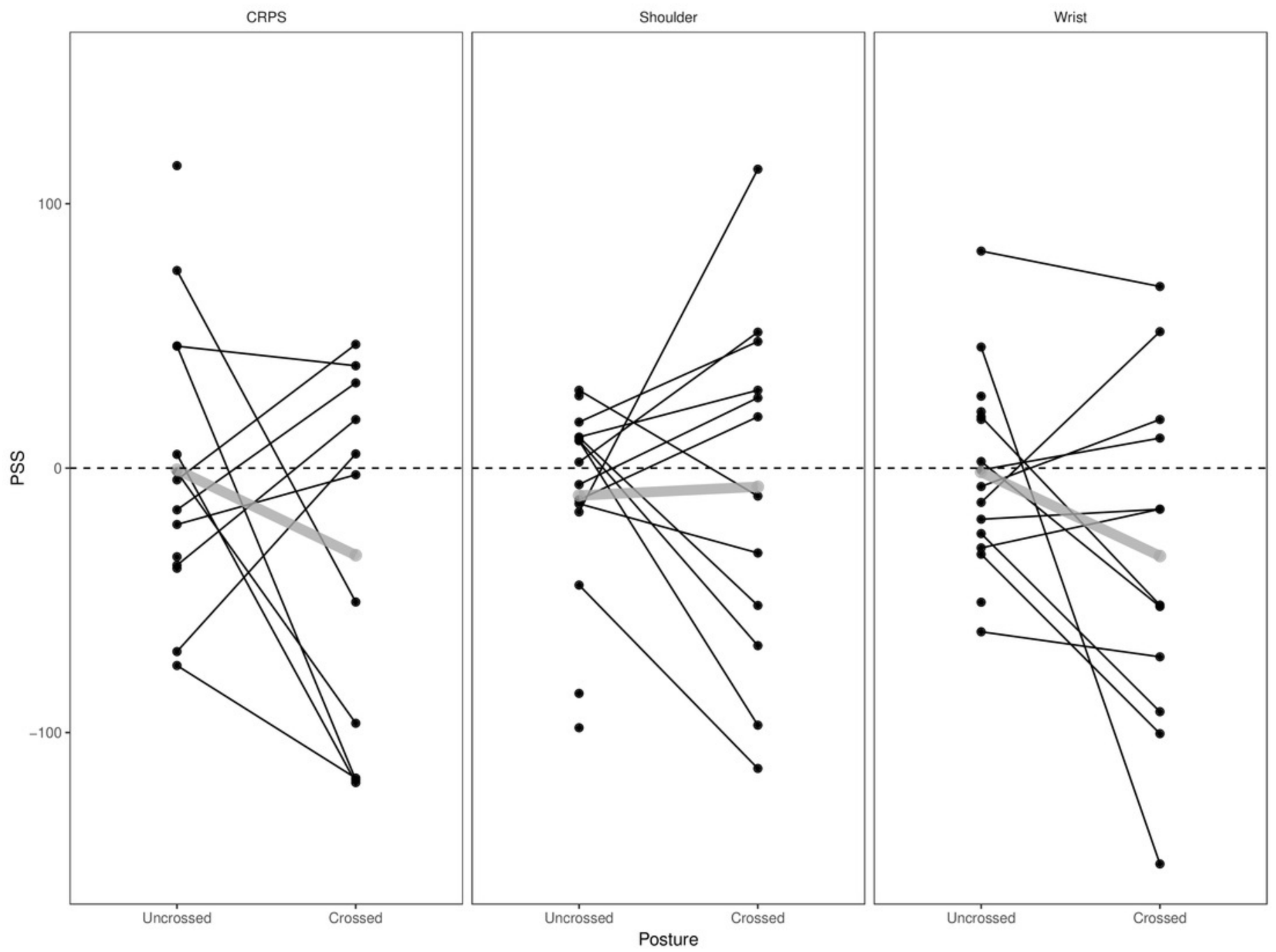


Figure 3

Observed PSS values in function of temperature difference and posture for the three patient groups.

The lines represent linear regression lines.

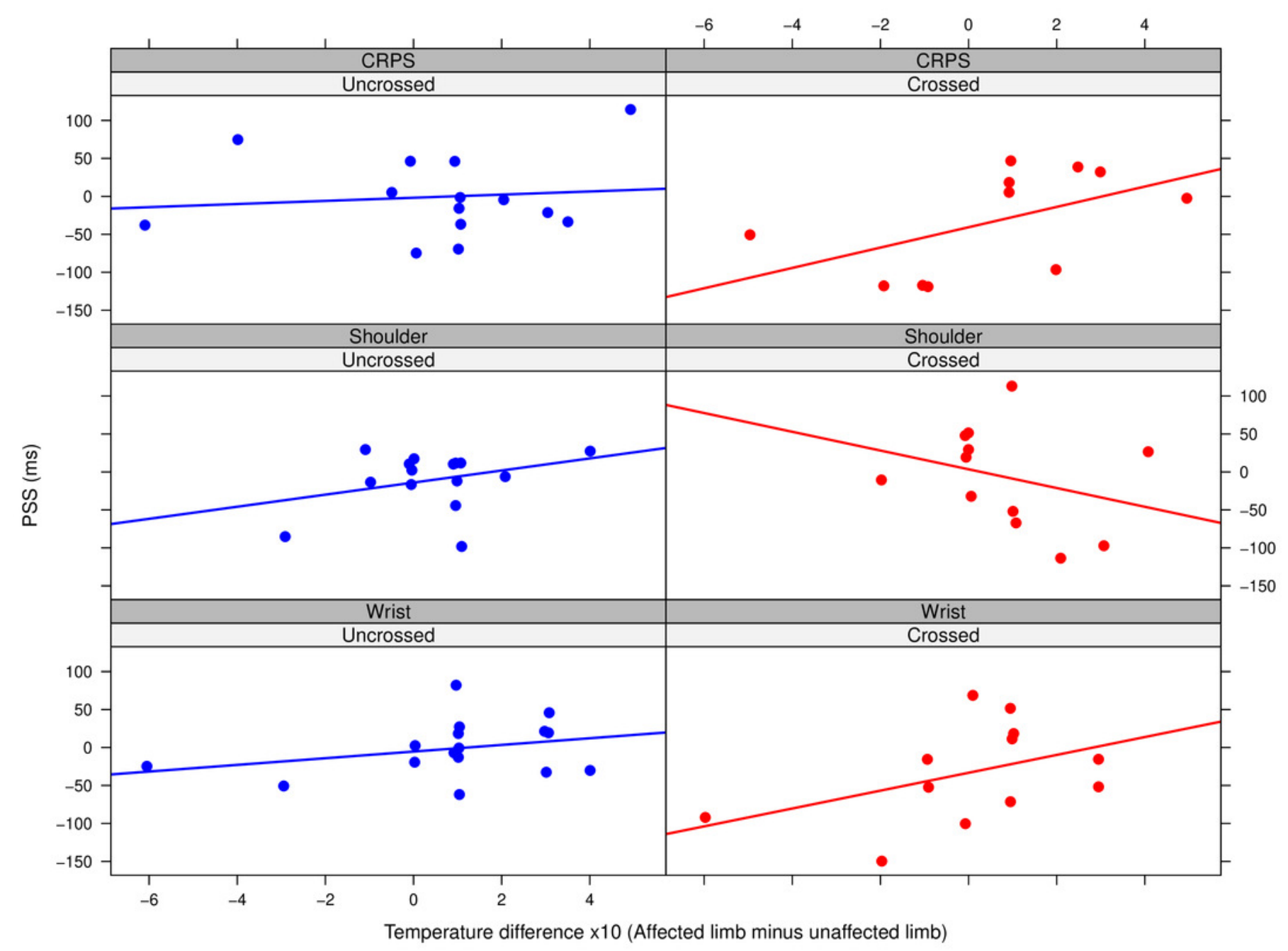


Figure 4

Observed PSS values in function of pain duration and posture for the three patient groups.

The lines represent linear regression lines

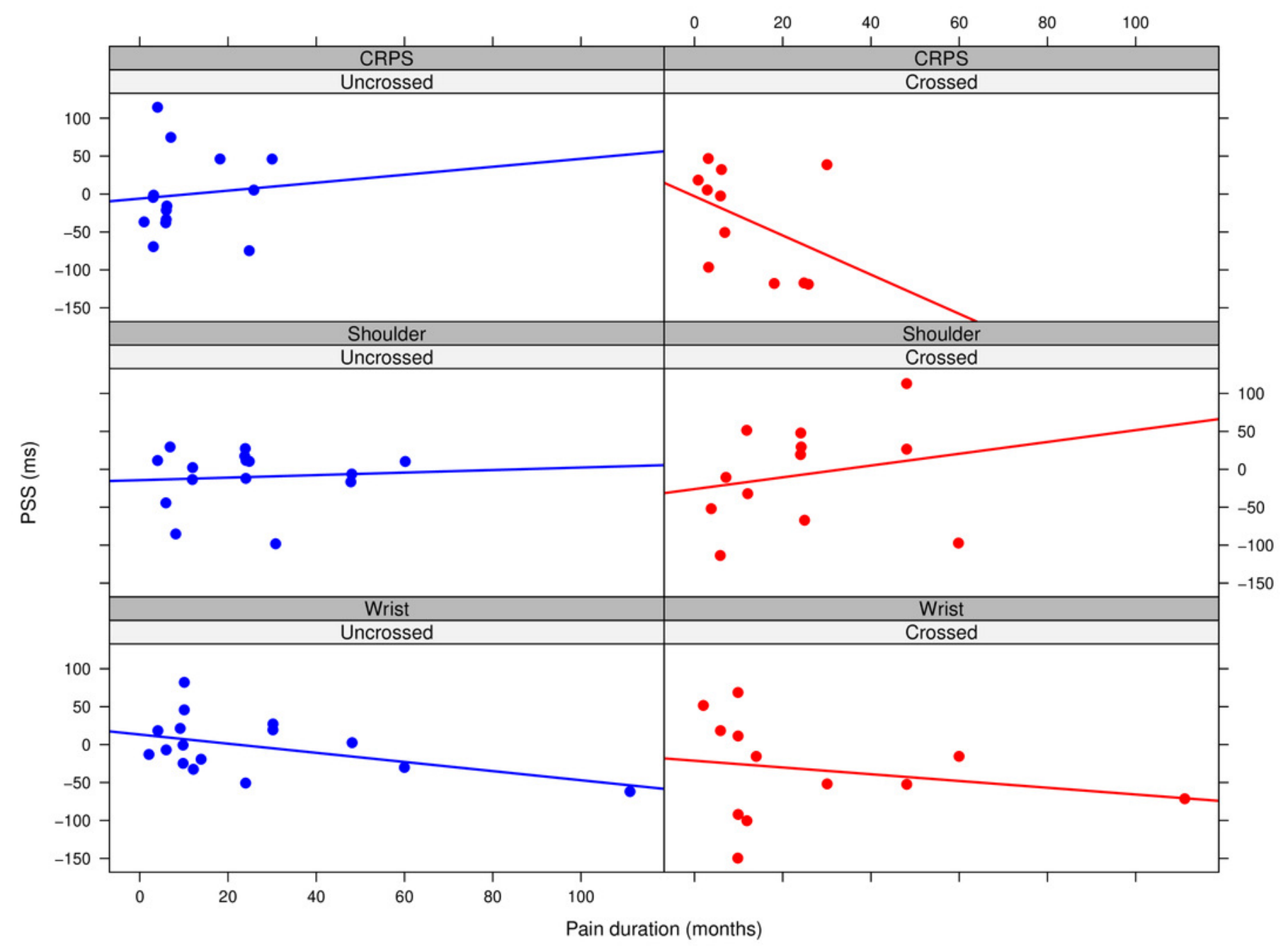


Figure 5

Individual and mean JND values.

Individual (black) and mean (grey) JND values per posture and per group.
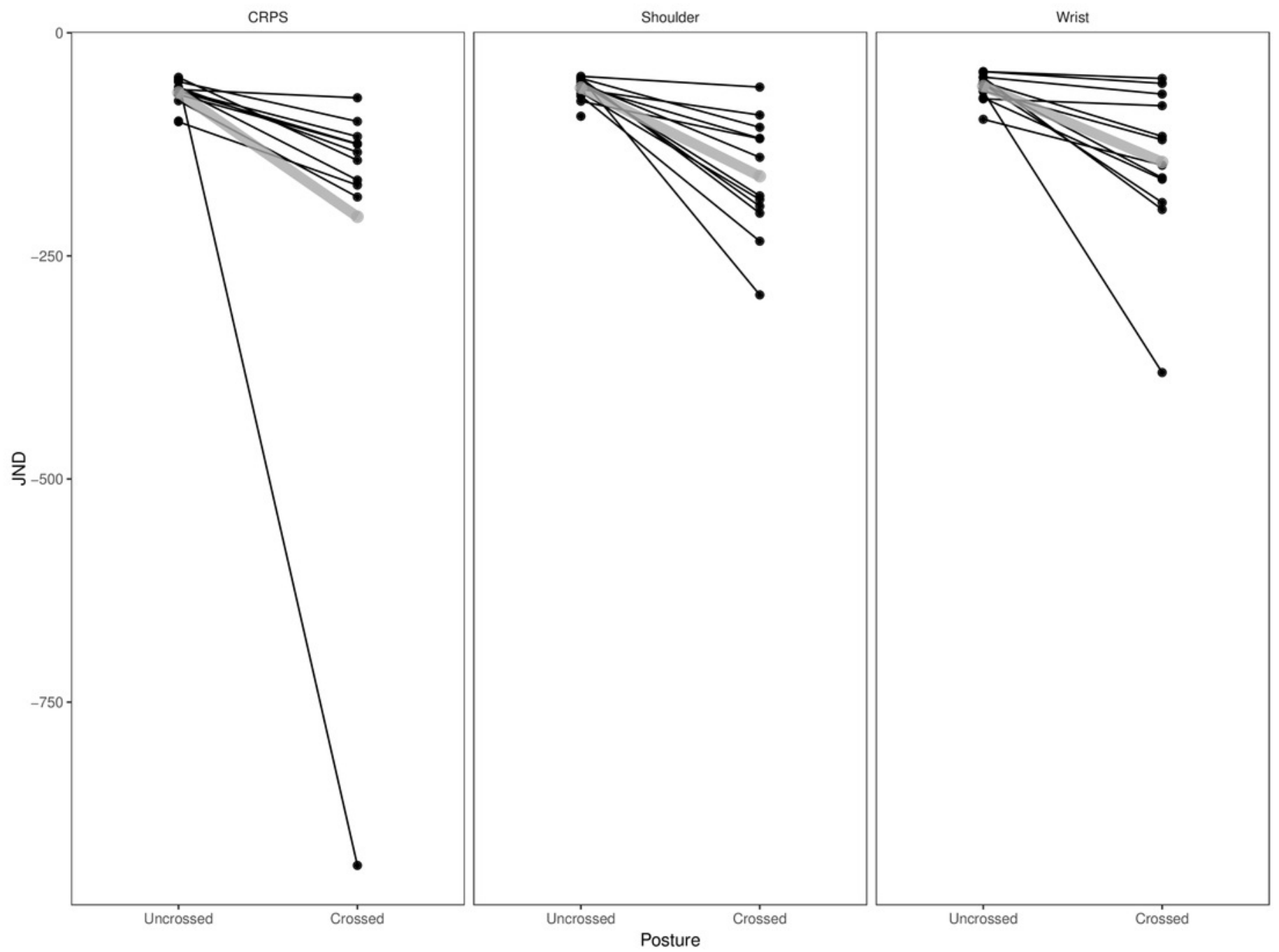


\section{Table $\mathbf{1}$ (on next page)}

Overview of patients characteristics for each patient group

Age in years; $F=$ Female; $M=$ Male; $R=$ right; ambi $=$ ambidextrous; $L=$ left; $N S=$ Not Specified. 'Hand dominance' based on Hand Dominance Questionnaire. 'PGS', Pain Grading Scale. PGS missing for 1 wrist pain patient. Remark: CRPS patient 4, 8 and 13 did not fulfill the research criteria for CRPS. Analysis were performed with and without including these patients. 


\begin{tabular}{|c|c|c|c|c|c|c|c|c|}
\hline & ID & Age/sex/handedness & $\begin{array}{l}\text { Location } \\
\text { of pain }\end{array}$ & Diagnosis & $\begin{array}{l}\text { Pain } \\
\text { duration } \\
\text { (months) } \\
\end{array}$ & $\begin{array}{l}\text { PGS } \\
\text { (grade score) }\end{array}$ & Other pain & Other \\
\hline \multirow[t]{8}{*}{ CRPS } & 1 & $62 / F / R$ & $\begin{array}{l}\text { R } \\
\text { wrist and } \\
\text { hand }\end{array}$ & CRPS & 4 & 3 & / & $\begin{array}{l}\text { dystionia } \\
\text { neck, familial } \\
\text { tremor }\end{array}$ \\
\hline & 2 & $37 / F / R$ & $\begin{array}{l}\text { R } \\
\text { elbow, } \\
\text { wrist, } \\
\text { hand, } \\
\text { pink }\end{array}$ & CRPS & 18 & 4 & R shoulder & / \\
\hline & 3 & $66 / F / R$ & $\begin{array}{l}\mathrm{R} \\
\text { wrist and } \\
\text { hand }\end{array}$ & CRPS & 6 & 4 & / & / \\
\hline & 4 & $68 / F / R$ & $\begin{array}{l}\text { R } \\
\text { wrist, } \\
\text { hand, } \\
\text { lower } \\
\text { arm }\end{array}$ & CRPS & 6 & 3 & / & fibromyalgia \\
\hline & 5 & $48 / F / R$ & $\begin{array}{l}\mathrm{L} \\
\text { wrist and } \\
\text { hand }\end{array}$ & CRPS & 3 & 4 & $\begin{array}{l}\text { L knee, L } \\
\text { frozen } \\
\text { shoulder }\end{array}$ & / \\
\hline & 6 & $45 / F / R$ & $\begin{array}{l}\mathrm{L} \\
\text { wrist and } \\
\text { hand }\end{array}$ & CRPS & 7 & 3 & / & / \\
\hline & 7 & 49/F/R & $\begin{array}{l}\mathrm{L} \\
\text { wrist and } \\
\text { hand }\end{array}$ & CRPS & 3 & 1 & $\begin{array}{l}\text { L frozen } \\
\text { shoulder }\end{array}$ & / \\
\hline & 8 & $45 / F / R$ & $\begin{array}{l}\text { R } \\
\text { hand, } \\
\text { wrist, }\end{array}$ & & 18 & 4 & $\begin{array}{l}\text { R frozen } \\
\text { shoulder }\end{array}$ & / \\
\hline
\end{tabular}




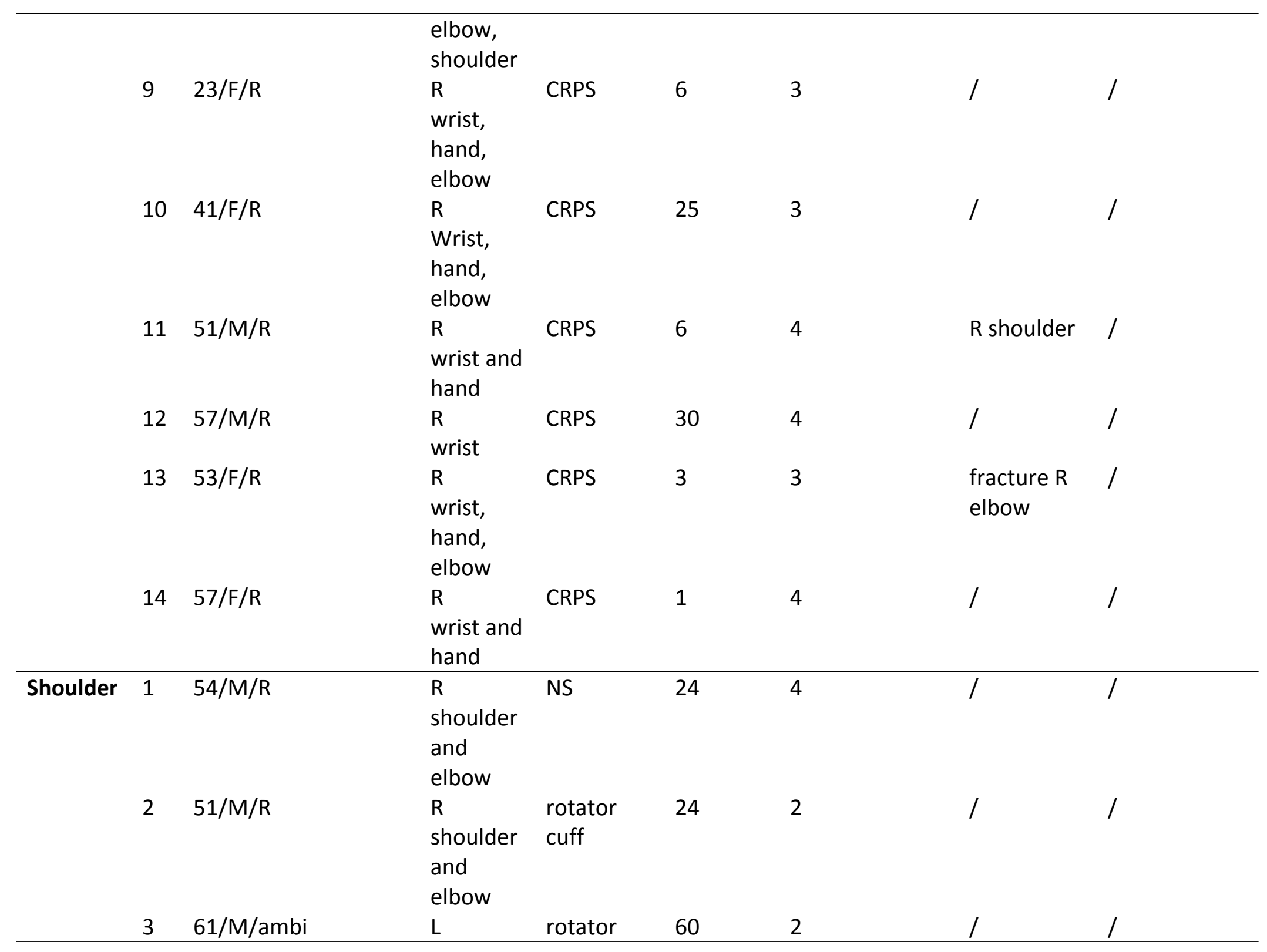




\begin{tabular}{|c|c|c|c|c|c|c|c|}
\hline & & shoulder & cuff & & & & \\
\hline 4 & 53/M/L & $\begin{array}{l}\text { L } \\
\text { shoulder }\end{array}$ & NS & 12 & 2 & / & / \\
\hline 5 & $41 / F / R$ & $\begin{array}{l}\mathrm{R} \\
\text { shoulder } \\
\text { and neck }\end{array}$ & $\begin{array}{l}\text { frozen } \\
\text { shoulder }\end{array}$ & 12 & 4 & / & / \\
\hline 6 & $40 / F / R$ & $\begin{array}{l}\text { L } \\
\text { shoulder }\end{array}$ & $\begin{array}{l}\text { frozen } \\
\text { shoulder }\end{array}$ & 48 & 2 & / & / \\
\hline 7 & $64 / M / L$ & $\begin{array}{l}\text { R } \\
\text { shoulder }\end{array}$ & NS & 4 & 4 & / & / \\
\hline 8 & $52 / \mathrm{M} / \mathrm{R}$ & $\begin{array}{l}\mathrm{R} \\
\text { shoulder }\end{array}$ & NS & 48 & 4 & / & / \\
\hline 9 & 46/F/L & $\begin{array}{l}\mathrm{R} \\
\text { shoulder }\end{array}$ & $\begin{array}{l}\text { frozen } \\
\text { shoulder }\end{array}$ & 8 & 4 & / & / \\
\hline 10 & $56 / F / R$ & $\begin{array}{l}\text { R } \\
\text { shoulder } \\
\text { and } \\
\text { elbow }\end{array}$ & $\begin{array}{l}\text { frozen } \\
\text { shoulder }\end{array}$ & 24 & 4 & $\begin{array}{l}\text { arthritis, } \\
\text { convulsions } \\
\text { hands }\end{array}$ & / \\
\hline 11 & $42 / M / R$ & $\begin{array}{l}\mathrm{L} \\
\text { shoulder }\end{array}$ & $\begin{array}{l}\text { frozen } \\
\text { shoulder }\end{array}$ & 25 & 2 & $\begin{array}{l}\text { chronic low } \\
\text { back pain }\end{array}$ & / \\
\hline 12 & 49/F/R & $\begin{array}{l}\text { R } \\
\text { shoulder }\end{array}$ & & 31 & 2 & / & / \\
\hline 13 & $44 / F / R$ & $\begin{array}{l}\mathrm{R} \\
\text { shoulder } \\
\text { and } \\
\text { elbow }\end{array}$ & $\begin{array}{l}\text { frozen } \\
\text { shoulder }\end{array}$ & 24 & 3 & & $\begin{array}{l}\text { scoliosis back } \\
\text { (no pain) }\end{array}$ \\
\hline 14 & $64 / F / R$ & $\begin{array}{l}\mathrm{L} \\
\text { shoulder } \\
\text { and } \\
\text { upper } \\
\text { arm }\end{array}$ & $\begin{array}{l}\text { frozen } \\
\text { shoulder }\end{array}$ & 6 & 4 & & hypothyroidie \\
\hline
\end{tabular}




\begin{tabular}{|c|c|c|c|c|c|c|c|c|}
\hline & 15 & $59 / F / R$ & $\begin{array}{l}\text { L } \\
\text { shoulder } \\
\text { and neck }\end{array}$ & $\begin{array}{l}\text { frozen } \\
\text { shoulder }\end{array}$ & 7 & 2 & I & I \\
\hline \multirow[t]{10}{*}{ Wrist } & 1 & $58 / F / R$ & $\begin{array}{l}\text { L } \\
\text { wrist }\end{array}$ & $\begin{array}{l}\text { malunion } \\
\text { fracture } \\
\text { wrist }\end{array}$ & 12 & 1 & 1 & $/$ \\
\hline & 2 & $52 / F / R$ & $\begin{array}{l}\mathrm{R} \\
\text { wrist }\end{array}$ & NS & 6 & 1 & I & I \\
\hline & 3 & $40 / F / L$ & $\begin{array}{l}\mathrm{R} \\
\text { wrist }\end{array}$ & $\begin{array}{l}\text { wrist } \\
\text { distortion }\end{array}$ & 10 & 4 & / & \\
\hline & 4 & $30 / F / L$ & $\begin{array}{l}\text { L } \\
\text { wrist }\end{array}$ & NS & 24 & 3 & I & I \\
\hline & 5 & $45 / \mathrm{M} / \mathrm{L}$ & $\begin{array}{l}\mathrm{L} \\
\text { wrist and } \\
\text { hand }\end{array}$ & $\begin{array}{l}\text { Fracture } \\
\text { wrist }\end{array}$ & 10 & 4 & I & I \\
\hline & 6 & $28 / F / R$ & $\begin{array}{l}\text { R } \\
\text { wrist, } \\
\text { elbow, } \\
\text { hand }\end{array}$ & NS & 30 & 4 & I & I \\
\hline & 7 & $26 / F /$ & $\begin{array}{l}\mathrm{L} \\
\text { wrist }\end{array}$ & $\begin{array}{l}\text { wrist } \\
\text { distortion }\end{array}$ & 10 & & I & I \\
\hline & 8 & $28 / \mathrm{M} / \mathrm{R}$ & $\begin{array}{l}\text { L } \\
\text { Wrist } \\
\text { and } \\
\text { lower } \\
\text { arm }\end{array}$ & $\begin{array}{l}\text { Fracture } \\
\text { wrist }\end{array}$ & 48 & 2 & / & / \\
\hline & 9 & $32 / F / R$ & $\begin{array}{l}\text { R } \\
\text { wrist, } \\
\text { elbow, } \\
\text { hand }\end{array}$ & $\begin{array}{l}\text { wrist } \\
\text { distortion }\end{array}$ & 14 & 1 & I & I \\
\hline & 10 & $53 / F / R$ & $\mathrm{~L}$ & tendonitis & 2 & 2 & / & / \\
\hline
\end{tabular}




\begin{tabular}{|c|c|c|c|c|c|c|c|}
\hline & & $\begin{array}{l}\text { wrist, } \\
\text { Lower } \\
\text { arm }\end{array}$ & & & & & \\
\hline 11 & $24 / F / R$ & $\begin{array}{l}\mathrm{L} \\
\text { wrist }\end{array}$ & NS & 9 & 1 & $\begin{array}{l}\text { low back } \\
\text { pain }\end{array}$ & / \\
\hline 12 & $59 / F / R$ & $\begin{array}{l}\text { R } \\
\text { wrist, } \\
\text { elbow, } \\
\text { hand }\end{array}$ & NS & 60 & 4 & / & / \\
\hline 13 & $26 / M / R$ & $\begin{array}{l}\mathrm{L} \\
\text { wrist }\end{array}$ & NS & 4 & 3 & / & I \\
\hline 14 & $45 / F / L$ & $\begin{array}{l}\mathrm{R} \\
\text { wrist and } \\
\text { hand }\end{array}$ & $\begin{array}{l}\text { tendonitis, } \\
\text { ehlers } \\
\text { danlos }\end{array}$ & 111 & 4 & L knee & I \\
\hline 15 & $40 / \mathrm{M} / \mathrm{L}$ & $\begin{array}{l}\mathrm{R} \\
\text { wrist }\end{array}$ & NS & 10 & 4 & / & / \\
\hline 16 & $51 / F / R$ & $\begin{array}{l}\mathrm{L} \\
\text { wrist }\end{array}$ & NS & 30 & 4 & / & / \\
\hline
\end{tabular}

Table 1. Overview of patient characteristics for each patient group. Age in years; $F=$ Female; $M=$ Male; $R=$ right; ambi = ambidextrous; $L=$ left; $N S=$ Not Specified. 'Hand dominance' based on Hand Dominance Questionnaire. 'PGS', Pain Grading Scale. PGS missing for 1 wrist pain patient.

Remark: CRPS patient 4, 8 and 13 did not fulfill the research criteria for CRPS. Analysis were performed with and without including these patients. 